\title{
METALURGIA PREHISPÁNICA EN LAS \\ SOCIEDADES COSTERAS DEL NORTE DE \\ Chile (QuebradA MAMilla, TOCOPILla)
}

\author{
Diego Salazar ${ }^{1}, V_{\text {Valentina Figueroa }}^{2}$, Benoit Mille ${ }^{3}$, Diego Morata ${ }^{4}$ y Hernán Salinas ${ }^{1}$
}

\section{* Introducción}

\begin{abstract}
Resumen
Se presentan evidencias directas e indirectas de actividades metalúrgicas por parte de poblaciones cazadoras, recolectoras y pescadoras de la costa arreica del norte de Chile, durante los períodos Intermedio Tardío y Tardío. Se discuten estos hallazgos para finalmente proponer una tradición metalúrgica local con características distintivas para las sociedades costeras, que complementa el conocimiento actual sobre el uso y significado de los metales en el Área Andina.

Palabras claves: metalurgia - sociedades costeras - cazadores recolectores - pescadores - norte de Chile - período Intermedio Tardío - período Tardío.
\end{abstract}

\begin{abstract}
We present direct and indirect evidences of metallurgical activities by hunter-gatherer and fishers populations of the arid coast of Northern

Chile during Late Intermediate and Late periods. We discuss these evidences and propose the existence of a local metallurgical tradition with particular characteristics for the coastal societies in this region.

This tradition complements current knowledge about the use and significance of metals in the Andes.
\end{abstract}

Key words: metallurgy - coastal societies - hunter gatherers - fishers Northern Chile - Late Intermediate Period - Late Period.

Recibido: febrero 2010. Aceptado: mayo 2010.
La metalurgia prehispánica en la costa del Norte Grande de Chile ha sido poco investigada por la arqueología. Sin embargo, algunos estudios, como los clásicos trabajos de Latcham (1936 y 1938), describen los objetos metálicos exhumados hasta entonces, entre Antofagasta y Caldera, así como los de Álvarez (1959) para la zona de Arica. Recientemente, nuevos estudios han sistematizado los registros de piezas metálicas provenientes de Arica (Figueroa 2010 Ms), Taltal (Núñez 1984, 1987) y Caldera (Latorre et al. 2007). No obstante, éstos se centran exclusivamente en objetos terminados, la mayoría de contextos funerarios o descontextualizados. En consecuencia, aún es poco lo que se sabe acerca de los procesos de producción de metales en la costa nortina, aunque existen antecedentes sobre la tecnología y producción de metales: En la década de 1980, Álvarez (1981, 1992-93) describe evidencias de metalurgia en la desembocadura de Camarones, las que posteriormente retoman y profundizan Schiappacasse y Niemeyer (1989), Muñoz (1989), Ponce y colaboradores (1996) y Figueroa y colaboradores (2009). Además, desde una visión tecnológica Durán y colaboradores (1980), realizan los primeros análisis metalográficos de anzuelos arqueológicos provenientes de Taltal y Caldera, así como Ponce (2002) hace esos análisis junto a otros de composición química, en mazas prehispánicas de Arica y de la costa sur peruana.

\footnotetext{
${ }^{1}$ Depto. de Antropología, Universidad de Chile. Ignacio Carrera Pinto 1045, Nuñoa, CHILE. Email: dsalazar@uchile.cl, tocopillasw@yahoo.es

${ }^{2}$ Université Paris i Panthéon-Sorbonne, UMR 8096, ARCHAM, 3 rue Michelet 75006 París, FRANCIA. Email: Valentina.Figueroa-Larre@ malix.univ-parisı.fr

3 Centre de Recherche et de Restauration des Musées de France, UMRı17 CNRS-Culture, 14 Quai F. Mitterrand, 75001 París, FRANCIA. Email: benoit.mille@culture.gouv.fr

4 Depto. Geología, Universidad de Chile. Beauchef 850, CHILE. Email: dmorata@cec.uchile.cl
} 
De acuerdo a estos antecedentes, hoy sabemos que la costa entre Arica y Caldera comparte una serie de categorías funcionales de objetos elaborados en metal (p.e., anzuelos y barbas de arpón, entre otros) por lo menos desde el período Intermedio Tardío (900-140o DC). Sin embargo, nada sabemos acerca de la posible producción local de estos objetos desde la quebrada de Camarones al sur, ya que el escaso conocimiento de la metalurgia prehispánica costera proviene del estudio de artefactos ya terminados, la mayoría analizados macroscópicamente y escasamente contextualizados. Para intentar llenar este vacío, en el año 2008 iniciamos un proyecto de investigación sobre la minería y la metalurgia indígena prehispánica en la costa de la II región de Chile, particularmente en la localidad de Tocopilla. ${ }^{5}$ Ahora presentamos los datos que obtuvimos en el marco de dicho proyecto y los discutimos considerando los conocimientos actuales en la región, todo lo cual nos lleva a pensar en la existencia de una tecnología metalúrgica propiamente costera durante los períodos alfareros tardíos.

\section{* ¿Metalurgia local o de tierras altas?}

En las escasas publicaciones referidas a colecciones metálicas de la costa norte de Chile, es evidente que estos artefactos son vistos como una importación desde otras zonas, desestimando la posibilidad de una industria local. Por ejemplo, Uhle en la década de 1910, refiriéndose a Taltal, señala en su correspondencia con Capdeville que "los objetos de cobre [de Taltal] comprueban la influencia diaguita desde el sur (Illapel) o del lado argentino" (Mostny 1964: 25); o bien que:

“...los objetos de bronce [cobre] que usted podrá encontrar en Taltal, presentaron todos los tipos atacameños o diaguites [sic] desarrollados en la región sur de Copiapó y La Serena [que hasta entonces no había sido estudiada] y de la región diaguite [sic] argentina" (Mostny 1964: 93).

\footnotetext{
5 Proyecto DI SOC 20-02: "Primeras investigaciones arqueometalúrgicas en la costa norte de la región de Antofagasta: Tocopilla", financiado por la Vicerrectoría de Investigación de la Universidad de Chile. Los análisis arqueometalúrgicos se realizaron en el marco del Proyecto FONDECYT 1080666: "Aproximaciones a la historia minero-metalúrgica indígena en la costa desértica del norte de Chile: Localidades de Taltal y Paposo", con el fin de comparar y caracterizar las metalurgias costeras entre Arica y Caldera.
}

Latcham tenía esa misma impresión. A comienzos del s. XX, incluso afirmaba que toda la metalurgia del norte de Chile era consecuencia de la conquista e influencia incaica y que previo a esos sucesos "ningún pueblo chileno practicaba el arte" de los metales (Latcham 1909: 243). Posteriormente, Latcham (1936 y 1938) acepta que la producción local de metales existió antes de los incas tanto en la región atacameña como diaguita. No obstante, mantendrá la idea de que en la costa de Chile no se produjeron metales prehispánicos:

"Sabemos a ciencia cierta que, ántes de la llegada a la costa de los aimaras, ninguno de los pueblos allí establecidos conocía el arte de fundir metales i que aun después jamás se esparcía más al sur esta industria. Es evidente entonces que aquellos objetos de metal que encontramos en las sepulturas preincásicas del litoral, han tenido que importarse. Su forma, composición ifactura nos indican su procedencia. Los encontrados en las provincias de Antofagasta, Atacama i Coquimbo son casi sin excepción de tipo Calchaquí; mientras que los de más al norte son de tipos peruanos conocidos como derivados de la época de Tiahuanaco" (Latcham 1910: 57-58).

Al igual que Uhle, Latcham terminará sosteniendo un origen diaguita para la metalurgia costera de Taltal:

"Creemos por varios motivos, que los objetos de metal de Taltal se deben más bien a importaciones diaguitas venidas del sur y no a influencias atacameñas llegadas del norte. No creemos que los objetos de metal hallados en Taltal fuesen fundidos alli mismo, porque no se han encontrado en la vecindad vestigios de minas, de hornillos, de escorias, ni de moldes que indicaran semejante elaboración" (Latcham 1938: 307).

Trabajos más recientes también han resaltado la presencia de metales alóctonos en la costa, basándose en criterios morfofuncionales, estilísticos y de composición química (presencia de estaño) que fueron producidos de preferencia en el Noroeste Argentino (Mayer 1986; Núñez 1987; González 1992; Tarragó et al. 1997; Latorre et al. 2007). Por su parte, Núñez (1984, 1987 y 2006), ha sugerido la existencia de colonias de tierras altas explotando los recursos mineros de la costa chilena, y en particular de Taltal poniendo nuevamente el énfasis en poblaciones alóctonas a la costa desértica.

Pero, en menor medida, también pueden rastrearse en la bibliografía interpretaciones que sugieren que, junto 
a la innegable presencia de metales alóctonos, también se desarrolló una industria de metales local. En efecto, ya Latcham sugería una hipótesis interesante respecto de los anzuelos de cobre:

"Estos últimos parecen haber sido de fabricación secundaria en muchas ocasiones, utilizando para este fin, las puntas de topu, o un zarcillo quebrado; el cual siendo de un material demasiado precioso para botarlo, se ha aprovechado en hacer otro objeto útil" (Latcham 1910: 52).

Si bien desestima un proceso productivo minero-metalúrgico propiamente tal en la costa, plantea la posibilidad de que objetos metálicos de las tierras altas se estén refundiendo en la costa para fabricar artefactos pesqueros. Núñez (1987) va aún más lejos al reconocer que junto a los metales de tierras altas, se estaría realizando en la costa de Taltal una metalurgia local, a raíz del hallazgo, comunicado por Latcham, de piezas metálicas con estaño (alóctonas) y sin estaño (que serían locales). También propone la existencia de comunidades de "pescadoresmineros" de la cultura Arica que, desde Lluta y Azapa, se desplazarían hasta Caleta Huelén e incluso Taltal para explotar recursos cupríferos locales de alta ley (1987: 89). Por otra parte, el estudio de Álvarez (1992-93) sobre los metales de Camarones plantea la posibilidad de diferenciar y reconocer en la manufactura de los objetos las tradiciones metalúrgicas locales, altiplánicas e incaicas. Para Álvarez, una metalurgia local asociada a los contextos de pescadores se manifestaría entre Arica y Camarones, considerando adicionalmente sus hallazgos en Terraza Sur de Camarones. Por último, también Latorre y colaboradores (2007) sugieren la existencia de una industria metalúrgica local en la costa de Caldera.

Si bien las ideas sobre el trabajo de metales en la costa se han visto desfavorecidas por el énfasis puesto en los metales alóctonos, en la actualidad existen evidencias que demuestran claramente la existencia de una metalurgia costera, avalando las observaciones de Álvarez y Núñez, entre otros. De hecho, se han registrado en forma recurrente instrumentos metálicos asociados a actividades productivas litorales desde Arica hasta Caldera (y aún más al sur), tales como anzuelos, arpones, barbas para arpones, barras y poteras, que se encuentran sistemáticamente asociadas en sepulturas $y / 0$ en sitios habitacionales a los objetos metálicos más conocidos (y seguramente importados) tales como anillos, tupu, placas, cuchillos, hachas, pinzas, manoplas y cinceles, entre otros. Pero ciertamente, el primer conjunto de artefactos mencionados no se registra en contextos de las tierras altas o del Noroeste Argentino ${ }^{6}$, ya que éstas no fueron poblaciones especializadas en la explotación de recursos costeros.

Los datos obtenidos de la desembocadura de la quebrada Camarones demuestran actividades metalúrgicas locales evidenciadas por una gran cantidad de restos de moldes con vitrificación interna, desechos del proceso metalúrgico y artefactos metálicos terminados (Muñoz 1989; Álvarez 1992-93; Ponce et al. 1996; Figueroa et al. 2010). Si bien estas evidencias fueron originalmente adjudicadas al período Tardío, el reciente estudio de las cuantiosas colecciones de artefactos metálicos de pesca en las colecciones del período Intermedio Tardío de Arica, así como su composición química, indican que su producción se inició por lo menos a comienzos del segundo milenio de nuestra era (Figueroa $2010 \mathrm{Ms}$ ).

Considerando todo lo anterior, quedan pocas dudas acerca de la existencia de una industria metalúrgica propiamente costera que coexiste con las tradiciones de tierras altas y del Noroeste Argentino, a lo menos en el extremo norte de Chile. Sin embargo, la situación en la costa desde quebrada Camarones al sur no es tan clara debido a la falta de información. Aun cuando solo recientemente la arqueología ha vuelto a desarrollar proyectos de investigación sistemáticos para los períodos alfareros de esta zona, no se conocen evidencias directas de actividades minero-metalúrgicas indígenas prehispánicas.?

Particularmente, en este trabajo nos interesa el caso de Tocopilla, y nos preguntamos ifueron los artefactos metálicos vinculados con la economía costera producidos en Camarones e intercambiados con las poblaciones locales que ocupaban los sectores ubicados al sur de esta quebrada? ¿Existió una metalurgia local paralela a la de Camarones? ¿Fueron estos implementos metálicos producidos

${ }^{6}$ La única excepción conocida a la fecha son dos anzuelos y una barrita encontrados recientemente en superficie en el sitio Finca de Chañaral (González com.pers. 2008).

7 Si bien existen una lingotera en el Museo Augusto Capdeville de Taltal, ésta no tiene procedencia conocida por lo que no puede descartarse que provenga de colecciones de Arica, Quillagua o San Pedro de Atacama. 
en los sectores de producción metalúrgica de la aldea La Capilla, en Quillagua? Estas preguntas son interesantes de responder, ya que la producción local de metales costeros en Camarones estaría a cargo de grupos pescadores semisedentarios que constituyeron una parcialidad dentro de los grupos agricultores-pescadores de Arica (Horta 2000). Pero en la costa ubicada al sur de Camarones las sociedades locales mantuvieron un modo de vida altamente móvil durante el período Intermedio Tardío (Salazar et al. 2009), conservando su independencia cultural respecto de los grupos agropastoriles del desierto atacameño, aun cuando entre ambos se desarrolló un fuerte intercambio de productos. Finalmente cabe preguntarse ¿las sociedades de cazadores recolectores móviles en la costa arreica también produjeron metales localmente durante el Intermedio Tardío, o bien los importaron de otros grupos socialmente más complejos?

Hasta el momento solo sabíamos que el cobre fue el principal mineral empleado en la fabricación de implementos de pesca metálicos en la costa arreica, pero aún no conocíamos dónde ni bajo qué sistemas de organización tecnológica estos fueron producidos. Los datos que presentamos a continuación permitirán elaborar las primeras hipótesis interpretativas al respecto, a partir de evidencia empírica directa.

\section{* Minerales y Metales en la Costa Norte de Antofagasta}

En el extremo norte de la costa de la región de Antofagasta, particularmente en el distrito de Tocopilla, existen importantes reservas de cobre en yacimientos estratoligados alojados en rocas volcánicas del Jurásico (andesitas y basaltos de la Formación La Negra). Este tipo de yacimiento constituye la segunda reserva cuprífera en importancia económica en Chile, después de los pórfidos (Vivallo y Henríquez 1998). Adicionalmente, en Tocopilla son frecuentes los yacimientos de cobre tipo vetas alojadas en rocas plutónicas del Jurásico Superior (dioritas, granodioritas y monzodioritas del Batolito de la costa de Tocopilla) que se introducen en la Formación La Negra (Boric et al. 1990; Vivallo y Henríquez 1998; Maksaev y Zentilli 2002). También se ha informado la presencia de depósitos exóticos que ocurren en rocas monzoníticas y monzodioríticas y que provienen posiblemente de yaci- mientos tipo veta cercanos (Zambra et al. 2007). Es así que este distrito destaca por ser uno de los más ricos en reservas de cobre, y por presentar yacimientos de alta ley y de fácil extracción en un contexto tecnológico prehispánico (Núñez 1987).

De acuerdo a lo anterior, no es de extrañar que Tocopilla constituya un distrito que históricamente ha estado vinculado a la actividad minera del cobre, siendo todavía hoy una de sus principales actividades económicas. Si bien existen estudios que permiten conocer parcialmente la historia de la explotación minera industrial y hasta cierto punto artesanal de Tocopilla (Arce 1997 [1930]; Bermúdez 1966; Cajías 1977; Recabarren 2002; Martínez et al. 2005), es poco lo que sabemos acerca de su historia minero-metalúrgica prehispánica. Por el momento no es posible determinar si los ricos depósitos mineros de la costa norte de la región de Antofagasta fueron o no explotados y procesados localmente antes de los españoles.

Al considerar las colecciones de objetos metálicos excavados en la costa, llama la atención que la mayoría de ellos se concentren en la zona de Arica y entre Mejillones y Caldera. Latcham (1936 y 1938) también menciona que en Cobija existen colecciones importantes, pero los resultados de trabajos recientes en el área no lo confirman. Lo cierto es que los metales prehispánicos que se conocen para la costa entre Mejillones y Caleta Huelén son escasos, lo cual también podría deberse a las escasas investigaciones efectuadas en la zona. Es en Caleta Huelén donde los metales son más abundantes. Las investigaciones de Spahni (1967) y Núñez (1971) han informado sobre la presencia de 16 anzuelos y cuatro placas en sepulturas, además de cuentas y restos de mineral de cobre (Núñez 1987: 88). Más al sur, la frecuencia de metales disminuye. Por ejemplo, en el Museo de Tocopilla no existen piezas metálicas provenientes de los alrededores de la ciudad, aun cuando hay antecedentes del hallazgo de algunos objetos de metal en las sepulturas destruidas durante la construcción del camino costero que va desde Tocopilla a Iquique, así como de dos objetos, un cincel y una hachuela, encontrados al sur de Tocopilla en el sitio Camping Fragüita, actualmente en exhibición en el museo mencionado. Más al sur de Tocopilla, en el distrito de Cobija, Bittman (1984) informa la presencia de escasos anzuelos de metal, al igual que Durán y colaboradores (2005) para Caleta Errázuriz, en la península de Mejillones. Pero, las recientes excavacio- 
nes sistemáticas en la costa de Cobija, entre Punta Atala y Punta Tames (Castro com. pers. 2010) ${ }^{8}$, no han reportado la presencia de metales, aun cuando el sitio Guasilla 27 ha sido caracterizado como:

“...una ocupación minera del periodo Colonial Temprano y/o posiblemente prehispánico, con piques mineros con evidencias de extracción de minerales, guairas y círculos de piedras que pudieran ser prehispánicos" (Aldunate et al. 2008: 108).

Como ya señalamos, los datos disponibles no permiten explicar satisfactoriamente la presencia de bienes metálicos en la desembocadura del río Loa, Cobija y en los alrededores de Tocopilla. Sin embargo, los resultados de nuestros estudios tienden a apoyar la idea de que los metales vinculados a la economía costera hayan sido producidos en Camarones, donde se conoce un centro de producción de importancia regional (Álvarez 1992-93; Figueroa 2010 Ms). Lo anterior se basa en observaciones morfológicas y análisis de composición química realizados en un anzuelo de Caleta Huelén depositado en una colección particular de Tocopilla. Estos análisis indican atributos morfológicos y tecnológicos muy similares a los de los anzuelos de Arica. ${ }^{9}$ Este anzuelo está elaborado en bronce estañífero, al igual que los de Arica, mientras que los minerales cupríferos utilizados son ricos en azufre (sulfuros de cobre), lo cual también ha sido sistemáticamente observado en el instrumental pesquero de Arica y Camarones (Figueroa $2010 \mathrm{Ms}$ ). De este modo, pareciera cobrar fuerza, la idea de Núñez sobre comunidades de pescadores-mineros provenientes de Arica asentados en Caleta Huelén, de acuerdo a su asociación en cementerios con cerámica San Miguel (Núñez 1987).

Pero, en contraste con lo anterior, nuestros trabajos en el sector norte de Tocopilla y particularmente en la desembocadura de la quebrada Mamilla, permiten abrir una nueva línea de interpretación, complementaria con la anterior. De recolecciones superficiales y excavaciones estratigráficas recuperamos no solo fragmentos de artefactos metálicos terminados (anzuelos), sino también restos de mineral de

8 Proyecto FONDECYT 1050991: "El desierto costero y sus vinculaciones con las tierras altas. De Cobija a Calama”, dirigido por Victoria Castro.

9 La ausencia de estudios sistemáticos de los desechos metalúrgicos de Quillagua (sitio La Capilla) impiden por ahora estimar si fue en dicha localidad donde se produjo el anzuelo de Caleta Huelén. cobre, prills o gotas de metal fundido, lingotillos de cobre metálico, desechos metalúrgicos y restos aberrantes de metal. En otros sitios costeros de la localidad también hemos detectado en superficie la asociación de minerales de cobre y prills metálicos. Todas estas evidencias avalan una actividad minero-metalúrgica local. A continuación caracterizaremos estos hallazgos de quebrada Mamilla y discutiremos en torno a su naturaleza cronológica y cultural.

\section{* La quebrada Mamilla}

Los sitios con evidencias minero-metalúrgicas estudiados por nosotros se emplazan en la desembocadura de la quebrada Mamilla (Figura 1). Esta quebrada se encuentra a unos $10 \mathrm{~km}$ al norte de la ciudad de Tocopilla, siguiendo la ruta costera que une a esta ciudad con Iquique. La quebrada tiene una extensión de poco más de $2 \mathrm{~km}$ en dirección E-O, y se ubica en una faja estéril de terreno del desierto costero (Salazar et al. 2009). Prospecciones sistemáticas en la quebrada identificaron un total de 14 sitios arqueológicos, de los cuales nueve mostraron evidencias de ocupación indígena prehispánica y/o colonial (Figura 2). Cuatro de estos sitios presentaron restos de actividades minero-metalúrgicas en superficie y tres de ellos también en estratigrafía. A continuación describimos brevemente dichos sitios:

\section{Sitio Mamilla I (7565733 N / 377285 E)}

Se emplaza en el sector bajo del cono detrítico de la quebrada Mamilla, ocupando una amplia dispersión de conjuntos aislados de estructuras pircadas. En total se contabilizaron 31 conjuntos arquitectónicos, los cuales agrupan un mínimo de una y un máximo de cuatro estructuras adyacentes, así como algunos muros aislados. Predominan las estructuras de muros bajos de una hilera y aparejos rústicos, en algunos casos aprovechando los grandes bloques rocosos naturales como uno o más de sus muros. Las plantas de las estructuras son preferentemente subcuadrangulares, subrectangulares e irregulares. Muchas de estas estructuras presentan sectores de basural ya sea un su interior o exterior, dentro de los cuales hay diverso material artefactual, además de restos óseos y malacológico. Los materiales culturales diagnósticos indican un predominio de ocupaciones durante los períodos prehispánicos tardíos ( $c a$. 1000-1550 DC), con sectores reocupados en épocas histó- 


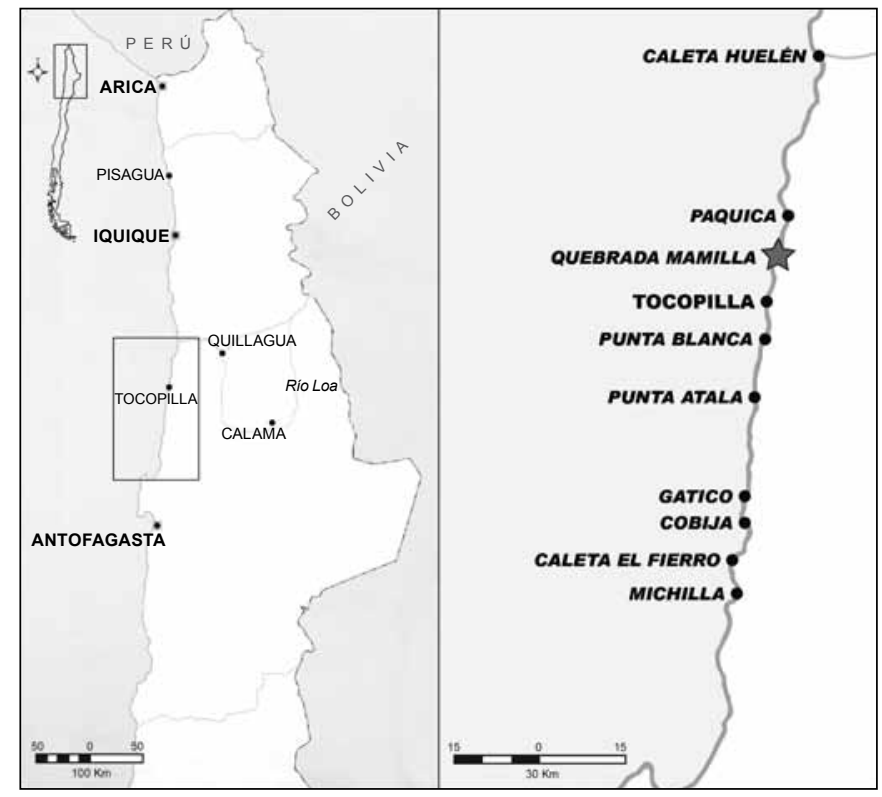

Figura 1. Área de estudio del proyecto y ubicación de la quebrada Mamilla, donde se encuentran los sitios mencionados en el texto.

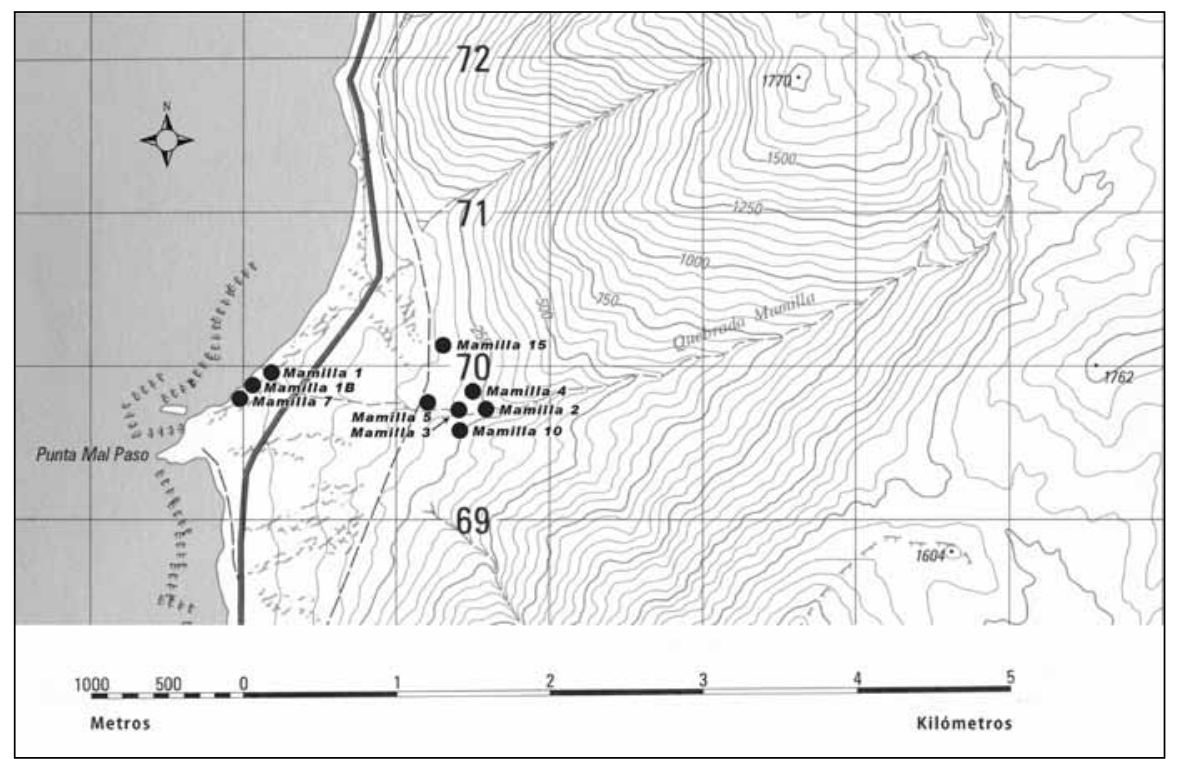

Figura 2. Sitios arqueológicos con ocupaciones prehispánicas identificados en la quebrada Mamilla.

ricas y subactuales (Salazar et al. 2009). Se realizaron cuatro pozos de sondeo en distintos conjuntos y sectores del sitio, los que mostraron escasa depositación subsuperficial. Aún así, en la superficie de diversos conjuntos arquitectónicos del sitio fue posible recolectar muestras de mineral de cobre, un cabezal de martillo lítico, gotas de cobre fundido (prills), fragmentos aberrantes de cobre metálico, un lingotillo y $\mathrm{fr}$ agmentos de artefactos, en particular anzuelos. Los pozos de sondeo se ubicaron en los lugares de mayor concentración de restos minero-metalúrgicos en superficie. 


\section{Sitio Mamilla 3 (7565727 N / 378040 E)}

Se ubica casi un kilómetro más arriba del sitio Mamilla 1, y entre el camino costero actual y el piedemonte de la cordillera de la costa. Está conformado por una serie de estructuras rectangulares y semicirculares, que fueron utilizadas como terrazas agrícolas en época subactual. No obstante, también se aprecian restos de estructuras habitacionales de data prehispánica, afectadas tanto por las estructuras históricas como por la habilitación de caminos vehiculares recientes. En el sitio se identificó cerámica de los períodos Intermedio Tardío, Tardío y Colonial, tanto en superficie como en los tres pozos de sondeo excavados (Salazar et al. 2009). A su vez, en superficie y en contextos estratigráficos en dos pozos excavados en un basural se identificaron restos de mineral de cobre, prills metálicos, un lingotillo, placas metálicas y fragmentos de anzuelos, junto a material lítico, malacológico y restos subactuales.

\section{Sitio Mamilla 7 (7565709 N / 377039 E)}

Se encuentra en el extremo suroeste de la quebrada, muy próximo a su desembocadura, a unos $100 \mathrm{~m}$ al oeste del sitio Mamilla 1. Es un conchal con alta densidad de materiales prehispánicos (lítico, cerámico malacológico, óseo) en superficie, y un potente depósito estratigráfico que supera los $2.5 \mathrm{~m}$ y que incluye capas correspondientes a los períodos Arcaico Tardío, Intermedio Tardío y Tardío (Salazar et al. 2009). En este sitio se excavó una cuadrícula de 2 x 1 m y se registraron tanto en superficie como en estratigrafía restos de mineral de cobre, una gota de metal fundido, un desecho de fundición de cobre metálico, dos láminas y cuatro fragmentos de anzuelos de metal, además de restos culturales y ecofactuales prehispánicos. Se cuenta con cuatro fechados absolutos, dos por radiocarbón y dos por termoluminiscencia.

\section{Sitio Mamilla 10 ( 7565590 N / 378093 E)}

Se emplaza en la ladera sur de la quebrada Mamilla, justo al frente del sitio Mamilla 3. Se trata de un asentamiento de carácter habitacional, formado por ocho estructuras pircadas de dimensiones variables. El material lítico y cerámico de superficie indica ocupaciones prehispánicas, pero fundamentalmente ocupaciones históricas (vidrio, loza, fragmentos de botellas de gres). También hay abun- dante material osteofaunístico (aves, vacunos, caprinos y caballo) y restos malacológicos. En este sitio realizamos un pozo de sondeo, del cual, tanto en superficie como en estratigrafía se recuperaron restos de mineral de cobre, trozos aberrantes de cobre metálico, un lingotillo y una cruz metálica.

\section{* Las Evidencias minero metalúrgicas}

Hemos destacado los sitios Mamilla 1, Mamilla 3, Mamilla 7 y Mamilla 10 pues son los que presentaron las más claras evidencias minero-metalúrgicas asociadas a materiales indígenas en la quebrada. Como ya fue indicado, tanto en superficie como en estratigrafía encontramos minerales de cobre, un martillo lítico, gotas o prills de cobre metálico, láminas de cobre metálico, lingotes de cobre metálico, desechos metalúrgicos, fragmentos de metal aberrantes y/o artefactos terminados de cobre metálico, tanto enteros como fragmentados (Tabla 1). Esto significa que en los sitios identificados están representadas varias de las fases de la cadena operativa minero-metalúrgica, lo cual constituye un hallazgo inédito para la arqueología de la costa del norte de la región de Antofagasta.

Con respecto a la fase minera de esta cadena, hasta el momento no hemos identificado evidencias directas (vale decir, minas o desmontes mineros) en Mamilla, aun cuando se registraron explotaciones de cobre del s. XIX en diversos puntos del curso superior de la quebrada. Es posible que evidencias anteriores puedan haberse visto afectadas por los intensos procesos erosivos causados por eventos catastróficos de tipo aluvional y coluvional que son característicos de este sector del litoral arreico. También es posible que las operaciones originales hayan sido de escasas dimensiones y que por lo tanto hayan dejado registros difíciles de discernir arqueológicamente. No obstante lo anterior, la presencia de mineral de cobre en la superficie y estratigrafía de los sitios identificados (ver Tabla 1) es una demostración indirecta de esta primera fase del proceso productivo minero-metalúrgico. Adicionalmente, el hallazgo de un martillo-percutor con restos de pigmento verde en su extremo activo en la superficie del sitio Mamilla 1 sugiere actividades de molienda de mineral de cobre in situ. Cabe mencionar que en el sector de Paquica, ubicado unos $10 \mathrm{~km}$ al norte de Mamilla, se encontraron dos martillos líticos en super- 


\begin{tabular}{|c|c|c|c|c|c|c|c|c|c|c|}
\hline \multirow{2}{*}{ Sitio } & \multirow{2}{*}{ Contexto } & \multicolumn{2}{|c|}{ Minería } & \multicolumn{3}{|c|}{ Metalurgia extractiva } & \multicolumn{2}{|c|}{ Elaboración } & \multicolumn{2}{|c|}{ Objeto terminado } \\
\hline & & Martillo & Mineral & Escoria & Prill & Lingote & Lámina & Frag. & Entero & Frag. \\
\hline \multirow{2}{*}{ Mamilla 1} & Superficie & 1 & 41 & o & 21 & o & 1 & 3 & $\circ$ & 2 \\
\hline & Estratigrafía & o & 2 & o & o & o & $\circ$ & ○ & o & o \\
\hline \multirow{2}{*}{ Mamilla 3} & Superficie & o & 6 & o & 8 & 1 & 2 & 1 & $\circ$ & 1 \\
\hline & Estratigrafía & o & 2 & o & o & o & 1 & 1 & $\circ$ & o \\
\hline \multirow{2}{*}{ Mamilla 7} & Superficie & o & 3 & o & o & o & o & 1 & o & 2 \\
\hline & Estratigrafía & o & 5 & o & 1 & o & ○ & 1 & o & 4 \\
\hline \multirow{2}{*}{ Mamilla 10} & Superficie & o & 5 & o & $\circ$ & 1 & o & 1 & $\circ$ & o \\
\hline & Estratigrafía & ○ & ○ & o & o & 1 & o & 1 & 1 & 1 \\
\hline \multicolumn{2}{|l|}{ TOTAL } & 1 & 64 & 0 & 30 & 3 & 4 & 9 & 1 & 10 \\
\hline
\end{tabular}

Tabla 1. Resumen de las evidencias minero-metalúrgicas encontradas en los sitios de la quebrada Mamilla.

ficie en el sitio Cabo Paquica 2 y varias lascas de martillos líticos en Cabo Paquica 1, en ambos casos asociados a mineral de cobre, fragmentos de alfarería del período Intermedio Tardío y restos malacológicos. Esta evidencia adicional sugiere que hubo minería de cobre prehispánica en la costa de Tocopilla. Esperamos que futuras prospecciones, que abarquen nuevos sectores, puedan identificar alguna mina indígena asociada a estos sitios.

La fundición de minerales y/o metales está representada principalmente por gotas de metal fundido (prills) en Mamilla 1, Mamilla 3 y Mamilla 7, lingotillos de metal en Mamilla 1, Mamilla 3 y Mamilla 10, y un desecho metalúrgico en Mamilla 7. Estas evidencias demuestran, que se realizaron actividades de fundición de cobre en la desembocadura de la quebrada Mamilla.

La producción de artefactos metálicos no está del todo representada en los sitios, aun cuando deben considerarse las láminas de cobre que pudieran ser el resultado de aquella actividad, así como trozos de metal aberrantes. Este tipo de evidencia se detectó en los sitios Mamilla 1, Mamilla 3, Mamilla 7 y Mamilla 1o. Finalmente, debe destacarse la presencia de artefactos metálicos terminados (en su mayoría fragmentados) en los sitios Mamilla 1, Mamilla 7 y Mamilla 1o, fundamentalmente anzuelos o partes de anzuelos. En la Tabla i se sintetizan los hallazgos minero-metalúrgicos de quebrada Mamilla.

Dado que muchas evidencias minero-metalúrgicas provienen de superficie, es difícil estimar su cronología exac- ta, lo cual representa un problema para determinar si la cadena operativa minero-metalúrgica descrita ocurrió durante la prehistoria o en momentos posteriores. Pese a que no todas las muestras son concluyentes al respecto, existen líneas de evidencia independientes que permiten sostener que buena parte de los hallazgos de quebrada Mamilla corresponden a épocas prehispánicas tardías.

En primer término, el control cronoestratigráfico logrado en el sitio Mamilla 7 permite obtener una datación segura para tres fragmentos de anzuelos metálicos, una gota de metal fundido o prill, un desecho de fundición y fragmentos de mineral de cobre. En el caso de los anzuelos, éstos provienen de tres capas distintas, dos de las cuales corresponden al período Intermedio Tardío y una al Tardío (Figura 3). En las capas correspondientes a este último, se encontró también la gota de cobre metálico (prill) y el desecho de fundición. Por último, en las capas correspondientes al Intermedio Tardío y en aquellas correspondientes al Tardío se encontraron fragmentos de mineral de cobre. Por sí mismas, estas evidencias demuestran la existencia de actividades metalúrgicas locales a lo menos durante el período Tardío, así como una posible actividad minera desde el Intermedio Tardío.

En segundo lugar, nuestras prospecciones en el segmento litoral entre Punta Atala por el sur y Cabo Paquica por el norte, se identificaron seis sitios en cuya superficie se asociaban mineral de cobre seleccionado y gotas de metal fundido o prills. De norte a sur, estos sitios son: Paquica Norte 1, Paquica Sur 3, Caleta Blanca 5, Punta Blanca, 


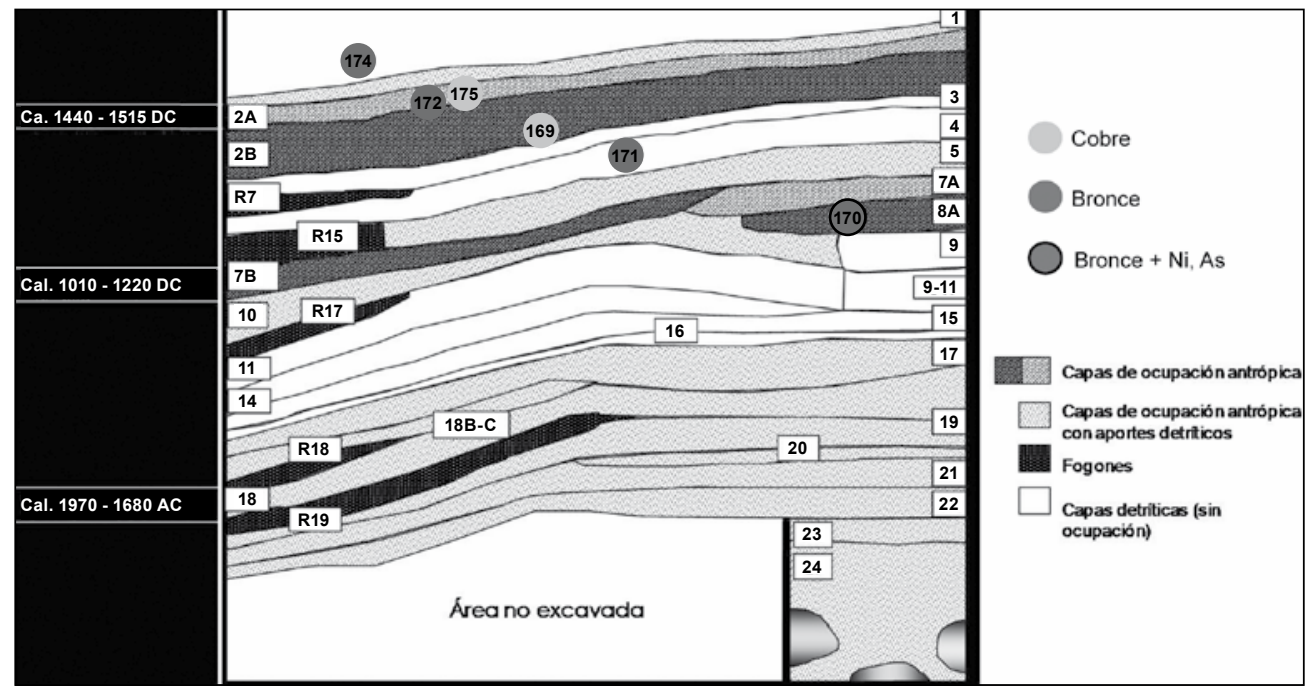

Figura 3. Perfil Este de la excavación del conchal Mamilla 7 y evidencias de composición química de los objetos y desechos metalúrgicos analizados.

Caleta Viuda 10 y Agua Dulce 7. Todos estos sitios presentaron cerámica de los períodos Intermedio Tardío y/o Tardío en superficie pero casi todos ellos total ausencia de materiales posteriores. En consecuencia, las evidencias de quebrada Mamilla no constituyen un hecho aislado a nivel del litoral de la costa norte, sino que parecen formar parte de un sistema de producción minero-metalúrgico prehispánico.

Como una tercera vía independiente de asignación cronológica de los restos minero-metalúrgicos en Mamilla, se realizó una serie de análisis de composición química en muestras seleccionadas. Su potencialidad para aportar información cronológica se desprende de: a) nuestro conocimiento actual acerca de las fechas de aparición de determinados tipos de aleaciones en los Andes Centro Sur (p.e., bronce estañífero); b) la comparación entre la composición química de los desechos metalúrgicos encontrados y la de artefactos metálicos históricos (anzuelos) provenientes de la quebrada, y c) la comparación de resultados entre los restos superficiales de la quebrada con los desechos metalúrgicos y artefactos terminados, bien controlados cronológicamente, de Mamilla 7.

Los resultados de los análisis, que presentamos en el siguiente acápite, indican que algunos de los prills y lingotillos superficiales de la quebrada son de bronce estañífero, al igual que fragmentos de objetos tanto en superficie como en estratigrafía del sitio Mamilla 7. Asimismo, en superficie también se detectaron algunos prills que arrojaron composiciones de cobre sin alear, lo cual se corresponde con lo observado en el desecho metalúrgico de la Capa 2A de Mamilla 7. En relacion a los prills de cobre sin alear, dos interpretaciones son posibles según su lugar en la cadena operativa: o bien son el resultado de la etapa de elaboracion de la aleacion del bronce (en ese caso no podemos excluir que dichos desechos sean ligados a los objetos en bronce); o bien las gotas provienen directamente de la etapa de fundición de los objetos en cobre sin alear.

Ahora bien, los análisis de composición química no solo tuvieron por objeto apoyar la asignación cronológica de los restos, sino muy en especial comprender mejor las características de esta metalurgia litoral de quebrada Mamilla. A continuación caracterizamos y comentamos en mayor detalle los resultados de estos análisis.

\section{* Procedimientos y resultados analíticos}

Desde hace unos 10 años la arqueometría se ha desarrollado de una forma notable: técnicas microdestructivas y no destructivas muy precisas (PIXE, ICP-AES, Raman, Microdifracción de rayos X), análisis isotópicos 


\begin{tabular}{|c|c|c|}
\hline Sitio & Contexto & Resultados \\
\hline Mamilla 1 & Conjunto 20, Superficial & Cuprita, Paratacamita, Yeso \\
\hline Mamilla 1 & Conjunto 17, Superficial & Cuprita, Melaconita, Paratacamita, Molibdenita, Vermiculita, Cuarzo \\
\hline Mamilla 3 & Sector B, Superficial & Dravita, Yeso, Clinocloro \\
\hline Mamilla 3 & Cuadrícula 1, Nivel 3-4, Capa 2B & Brochantita, Paratacamita, Atacamita \\
\hline Mamilla 3 & Cuadrícula 3, Nivel 3, Capa 2 & Atacamita, Cuarzo \\
\hline Mamilla 7 & Cuadrícula 1, Nivel 1, Capa 2 & Hematita, Malaquita, Alabandita, Pirolusita \\
\hline Mamilla 7 & Cuadrícula 1, Nivel 7-8, Capa 8 & Hematita, Paratacamita, Malaquita \\
\hline Mamilla 7 & Cuadrícula 1, Nivel 8, Capa 8A & Cuarzo, Ankerita, Albita, Caolinita \\
\hline Mamilla 7 & Cuadrícula 1, Nivel 10, Capa 9 & Paratacamita, Paracoquimbita. \\
\hline
\end{tabular}

Tabla 2. Resultados de los análisis de Difracción de Rayos X en muestras minerales de quebrada Mamilla.

y técnicas de imagen $3 \mathrm{D}$, entre otras. En el caso de los análisis físicoquímicos que nos interesan en esta oportunidad, las técnicas disponibles dan una amplia gama de informaciones sobre las distintas etapas de la cadena operativa. Los análisis pueden dar información sobre la composición, y en consecuencia, brindar indicios sobre la procedencia de la materia prima basándose en la relación aparente entre un mineral y el objeto terminado, encontrando los elementos traza de los minerales conservados en el metal después de la reducción o de la fusión. En este contexto, el objetivo de nuestro estudio arqueométrico ha sido, por una parte, caracterizar la procedencia y la circulación de las materias primas metálicas, y por otra, identificar las técnicas de fabricación de los metales, con el fin de comprender las diversas tradiciones tecnológicas del litoral. Para ello, hemos desarrollado una metodología de estudio para las metalurgias prehispánicas que en esta ocasión integró el análisis de minerales, desechos de producción y artefactos terminados. Mientras los primeros fueron sometidos a Difracción de Rayos X, los desechos metalúrgicos y los objetos metálicos fueron analizados mediante el método PIXE, microscopía electrónica de barrido (SEMEDX) y metalografías. ${ }^{10}$ A continuación se sintetizan los procedimientos y resultados de estos análisis.

\footnotetext{
${ }^{10}$ Estos análisis han sido desarrollados paralelamente en el Laboratorio Centre de Recherche et Restauration des Musées de France ( $\mathrm{C}_{2} \mathrm{RMF}$ ), en el Laboratorio de Microscopía Electrónica de Barrido y Microanálisis EDS de la Pontificia Universidad Católica de Chile, en el Laboratorio del Sernageomin y en el Departamento de Geología de la Universidad de Chile.
}

\section{Minerales}

Se realizaron nueve análisis mediante Difracción de Rayos X (método de polvo policristalino) en restos de mineral de cobre, con el fin de determinar la naturaleza mineralógica de los mismos. Las muestras seleccionadas provenían de la superficie de los sitios Mamilla 1 y Mamilla 3, además de muestras en estratigrafía de Mamilla 3 y Mamilla 7. Todos los análisis se realizaron en el Laboratorio de Difracción de Rayos X del Servicio Nacional de Geología y Minería (Sernageomin), a cargo de la Dra. Eugenia Fonseca. Las muestras seleccionadas fueron pulverizadas bajo 200 mallas y luego analizadas en un equipo Panalytical modelo X'Pert PRO, empleando el programa High Score Plus para la interpretación de resultados. En la Tabla 2 se sintetizan los resultados obtenidos. En todas las muestras analizadas se han identificado fases oxidadas de minerales de $\mathrm{Cu} y$, en términos generales, puede afirmarse que las fases minerales presentes son típicas de mineralizaciones de cobre de la cordillera de la Costa del área de Tocopilla y que, por lo tanto, bien pudieron haber sido procurados localmente. Las únicas excepciones podrían corresponder a la muestra superficial de Mamilla 3 y a la del Conjunto 17 de Mamilla 1, también superficial, en las que se ha identificado la presencia de dravita (variedad de turmalina) y molibdenita $\left(\mathrm{MoS}_{2}\right)$. Ambas fases minerales son más características de depósitos pórfidos, ausentes en la zona de estudio de la cordillera de la Costa del área de Tocopilla, por lo que su presencia en las muestras analizadas puede considerarse alóctona. 


\section{Desechos metalúrgicos, lingotes y anzuelos}

Se analizaron muestras metálicas tanto de superficie como de estratigrafía de los sitios Mamilla 1, Mamilla 3 y Mamilla 7. Un anzuelo de Caleta Huelén fue agregado como objeto de comparación. Los objetos analizados corresponden básicamente a fragmentos de anzuelos $(n=7)$, fragmentos de lámina o placa $(\mathrm{n}=2)$, gotas de cobre metálico o prills $(\mathrm{n}=2)$, lingotillo $(\mathrm{n}=1)$ y desecho metalúrgico $(\mathrm{n}=1)$.

a) Composición química. A continuación se ofrece la totalidad de los resultados obtenidos a partir del método PIXE y de los análisis por SEM-EDX (Tabla 3). En el caso del método PIXE, se determinó la composición elementaria a partir de rayos $\mathrm{X}$ inducidos por un haz de protones de $3 \mathrm{MeV}$ producidos por el acelerador linear AGLAE del C2RMF según el protocolo adaptado al análisis de las aleaciones de cobre.

La composición química permite identificar grupos metálicos homogéneos entre ellos. Así, hemos observado que existen por lo menos tres tipos de metales que se utilizaron en la costa de Tocopilla durante los períodos alfareros tardíos, dos de ellos representados en los sitios Mamilla 1 y Mamilla 3, y tres de ellos en Mamilla 7.

Si consideramos en más detalle los resultados del análisis composicional, tanto con el método PIXE como con microscopía electrónica de barrido, de los fragmentos de anzuelos de Mamilla 7 encontrados en estratigrafía, observamos que el anzuelo de la Capa 8A (PML170) fue elaborado a partir de un bronce estañífero con impurezas de níquel y arsénico. Este tipo de composición química es muy poco frecuente en los Andes Centro Sur, pero ha sido reportada en algunos objetos de San Pedro de Atacama vinculados a la esfera de interacción Tiwanaku (Lechtman 2003; Lechtman y McFarlane 2005). La fecha que se asocia a este hallazgo es coherente con lo anterior, si bien ligeramente más tardía. El hecho de que ningún desecho metalúrgico o mineral encontrado en los sitios de la quebrada exhiba el niquel asociado al arsénico, permite sugerir que el metal no es de procedencia local. Volveremos sobre este tema más adelante. Pero la situación es diferente en el caso de los otros dos anzuelos (PML171 y PML172) encontrados en estratigrafía y asociados a ocupaciones prehispánicas. Como ya se señaló, éstos están compuestos por una aleación de cobre y estaño (bronce estañífero), y algunos de los desechos metalúrgicos de la quebrada, tanto en superficie como en estratigrafía muestran la presencia de estos mismos componentes químicos.

Por otra parte, si observamos la composición química del anzuelo metálico histórico de Mamilla 3 (PML309), es interesante notar que éste se elaboró en cobre sin alear, pero sus impurezas no se asemejan a aquellas detectadas en la lámina (PML169) y en el desecho de fundición de cobre sin alear de Mamilla 7 (PML175). La composición del anzuelo histórico es significativamente parecida a la de otro anzuelo histórico estudiado por nosotros en Taltal (Figueroa et al. 2009). Por lo tanto, la composición química de los artefactos metálicos no se asemeja a la de los desechos metalúrgicos y artefactos metálicos prehispánicos de la quebrada, mientras que hay mayores similitudes composicionales entre el desecho metalúrgico de cobre sin alear de la Capa 2 (PML170) y las evidencias superficiales de Mamilla.

En síntesis, considerando: a) los resultados de las muestras en estratigrafía bien controlada cronológicamente (desechos de fundición); b) las evidencias superficiales de eventos de fundición en sitios costeros sin ocupación histórica, y c) la correspondencia entre las composiciones químicas de los materiales en estratigrafía con aquellos de superficie, concluímos que una parte importante de los desechos minero-metalúrgicos de la quebrada Mamilla corresponden a actividades productivas prehispánicas tardías. Se trata de las primeras evidencias de este tipo de actividad en la costa arreica del norte de Chile.

b) Exámenes metalográficos. La metalografía permite determinar los procesos a través de los cuales se fabricaron los objetos metálicos. Esta técnica puede proponer una lectura de los cambios de las técnicas de fabricación en el tiempo (Rovira y Gómez 2003: 159). Se han realizado exámenes metalográficos de algunos objetos de la serie de Mamilla, específicamente de los desechos metalúrgicos (Figura 4) y de anzuelos (Figuras 5 y 6). Los cortes fueron efectuados con una sierra de diamante de $0.3 \mathrm{~mm}$ de espesor a velocidad lenta. La localización del corte milimétrico depende de la problemática específica sobre una categoría de objeto dado. En nuestro caso, hemos favorecido el corte longitudinal y transversal para el estudio de los anzuelos. Cada muestra fue colocada en un molde individual adaptado a las porta muestras de la pulidora y 
a)

\begin{tabular}{|c|c|c|c|c|c|c|c|c|c|c|c|c|c|c|}
\hline $\mathbf{N}^{\circ}$ inv. & análisis & Objeto & Sitio & Técnica analitica & Si & P & $\mathrm{s}$ & $\mathrm{Cl}$ & $\mathbf{K}$ & $\mathrm{Ca}$ & Ti & $\mathrm{v}$ & $\mathrm{Cr}$ & Mn \\
\hline PML 173 & PIXE09-04deco12 & frag. vástago de anzuelo & Mamilla 1 & PIXE & 0,1 & 0,04 & 0,2 & 2,01 & 0,81 & $<0,03$ & & & & $<0,006$ \\
\hline 67578 & PIXEo9-16jano24 & lingotillo & Mamilla $_{3}$ & PIXE & 0,2 & $<0,03$ & 0,4 & 0,2 & 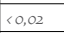 & 0,08 & $\begin{aligned}<0,006 \\
\end{aligned}$ & $\begin{aligned} 0,008 \\
\end{aligned}$ & $\begin{aligned}<0,003 \\
\end{aligned}$ & 80,004 \\
\hline 67577 & PIXEo9-16jano27 & prill & amilla 3 & PIXE & 0,1 & $<0,02$ & 0,3 & 0,1 & $<0,02$ & $\begin{array}{c}0,04 \\
\end{array}$ & $\langle 0,01$ & $<0,005$ & $<0,004$ & $<0,004$ \\
\hline PML309 & PIXEo9-16jano43 & frag. vástago de anzuelo & milla 3 & PIXE & 0,09 & $\begin{array}{r}<0,03 \\
\end{array}$ & $\begin{array}{r}0,03 \\
\end{array}$ & 0,4 & $\begin{array}{r}0,007 \\
\end{array}$ & $\begin{array}{c}<0,03 \\
\end{array}$ & \begin{tabular}{r|r}
0,007 \\
\end{tabular} & 00,005 & $\begin{array}{r}0,008 \\
\end{array}$ & $<0,005$ \\
\hline PML 310 & PIXE09-2ijano60 & lámina & Mamilla 3 & PIXE & $<0,08$ & $<0,04$ & 0,08 & 1,4 & $\langle 0,02$ & $\begin{array}{c}<0,04 \\
\end{array}$ & $\begin{array}{l}<0,005 \\
\end{array}$ & $<0,010$ & $\begin{array}{r}<0,008 \\
\end{array}$ & 80,007 \\
\hline PML & PIXEo9-16jano 44 & frag. vást. & Mamilla 7 & PIXE & $\begin{aligned}<0,09 \\
\end{aligned}$ & $<0,05$ & 0,3 & 6,4 & $<0,1$ & $<0,08$ & $\langle 0,01$ & \begin{tabular}{|l|l|}
$<0,009$ \\
\end{tabular} & 20,01 & $\angle 0,01$ \\
\hline PML 169 & PIXE09-04decoo9 & lámina & Mamilla 7 & PIXE & $<0,04$ & $<0,04$ & 0,49 & 4,94 & 0,49 & 0,099 & & & & $<0,01$ \\
\hline PML 170 & MEB_PML170 & frag. vástago de anzuelo & Mamilla 7 & SEM-EDX & & & & 0,5 & & & & & & \\
\hline PML 171 & PIXEo9-O4deco11 & frag. vástago de anzuelo & Mamilla 7 & PIXE & $<0,06$ & $<0,04$ & 0,69 & 2,46 & 2,26 & $<0,2$ & & & & 20,01 \\
\hline PML 172 & PIXEo9-04deco13 & frag. vást: & Mamilla 7 & PIXE & 0,62 & $<0,03$ & $<0,03$ & 0,21 & $<0,02$ & $\begin{array}{c}<0,07 \\
\end{array}$ & & & & $<0,008$ \\
\hline PML 174b & PIXEo9-04deco15 & lámina & Mamilla 7 & PIXE & $<0,10$ & $\begin{array}{r}<0,03 \\
\end{array}$ & $<0,09$ & 0,82 & $<0,05$ & $<0,08$ & & & & $<0,01$ \\
\hline PML 175 & PIXE09-04deco16 & goterón & Mamilla 7 & PIXE & $<0,07$ & $\begin{array}{r}0,03 \\
\end{array}$ & $<0,02$ & 0,1 & $<0,01$ & $<0,009$ & & & & $<0,01$ \\
\hline 67580 & PIXEo9-16janoo9 & frag. vástago de anzuelo & \begin{tabular}{|l} 
Caleta Huelén \\
\end{tabular} & PIXE & $<0,05$ & $\begin{array}{r}0,03 \\
\end{array}$ & $\begin{aligned}<0,03 \\
\end{aligned}$ & $\begin{array}{lll}<0,01 \\
\end{array}$ & $\langle 0,01$ & $<0,08$ & \begin{tabular}{ll|l}
$<0,009$ \\
\end{tabular} & \begin{tabular}{|c|c|}
$<0,009$ \\
\end{tabular} & \begin{tabular}{rl|l|}
$<0,007$ \\
\end{tabular} & $<0,007$ \\
\hline
\end{tabular}

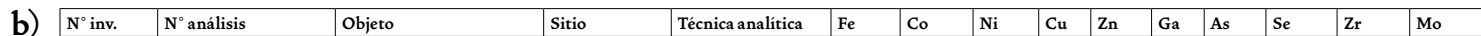

\begin{tabular}{|c|c|c|c|c|c|c|c|c|c|c|c|c|c|c|}
\hline & & & & & & & & & & & & & & \\
\hline PML 173 & PIXEo9-04deco12 & frag. vástago de anzuelo & \begin{tabular}{|l|} 
Mamilla 1 \\
\end{tabular} & PIXE & 0,1 & 0,1 & $<0,02$ & 94,4 & $<0,1$ & & 2,01 & $<0,05$ & & \\
\hline 67578 & PIXEog-16jano24 & lingotillo & Mamilla 3 & PIXE & 0,3 & 0,03 & \begin{tabular}{|c|c|c|}
$<$ \\
\end{tabular} & 98,8 & $<0,09$ & $<0.2$ & $<0,07$ & 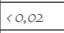 & $<0,006$ & $<0,004$ \\
\hline 67577 & PIXEog-16jano27 & prill & Mamilla 3 & PIXE & $\begin{aligned}<0,005 \\
\end{aligned}$ & $\begin{aligned} 0,004 \\
\end{aligned}$ & \begin{tabular}{rl|}
$<0,01$ \\
\end{tabular} & 96,5 & $<0,08$ & 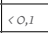 & 20,05 & 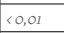 & $<0,004$ & $\begin{array}{r}<0,003 \\
\end{array}$ \\
\hline PML309 & PIXEog-16jano43 & \begin{tabular}{|l|} 
frag. vástago de anzuelo \\
\end{tabular} & Mamilla 3 & PIXE & $<0,01$ & $<0,005$ & $\begin{array}{cc}<0,02 \\
\end{array}$ & 98,1 & $<0,1$ & $<0,2$ & 1,1 & 0,06 & $<0,002$ & $<0,005$ \\
\hline PML310 & PIXEo9-21jano60 & lámina & Mamilla 3 & PIXE & 0,5 & $<0,02$ & \begin{tabular}{c|c|c|}
0,03 \\
\end{tabular} & 97,9 & $<0,07$ & $<0,1$ & $<0,04$ & $<0,01$ & $<0,006$ & $<0,002$ \\
\hline PML 311 & PIXEog-16jano44 & frag. vástago de anzuelo & Mamilla 7 & PIXE & 0,09 & $<0,008$ & $\begin{aligned}<0,03 \\
\end{aligned}$ & 82,9 & $<0,02$ & $<0,2$ & $\angle 0,1$ & 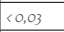 & $<0,009$ & $<0,006$ \\
\hline PML 169 & PIXEog-04decoo9 & lámina & Mamilla 7 & PIXE & $<0,04$ & $<0,02$ & $<0,04$ & 91,1 & $<0,04$ & & 0,99 & $<0,06$ & & \\
\hline PML 170 & MEB_PML170 & frag. vástago de anzuelo & Mamilla 7 & SEM-EDX & & & 0,5 & 85,7 & & & 0,1 & & & \\
\hline PML 171 & \begin{tabular}{|l|l|} 
PIXEo9-04deco11 \\
\end{tabular} & frag. vástago de anzuelo & Mamilla 7 & PIXE & 0,88 & $\begin{array}{r}0,02 \\
\end{array}$ & $<0,05$ & 81,2 & $<0,06$ & & $<0,1$ & $<0,02$ & & \\
\hline PML 172 & PIXEog-04deco13 & frag. vástago de anzuelo & Mamilla 7 & PIXE & $<0,02$ & $<0,007$ & $<0,04$ & 92,5 & $<0,1$ & & $<0,05$ & 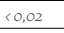 & & \\
\hline PML 174b & PIXEo9-04deco15 & lámina & Mamilla 7 & PIXE & $<0,01$ & $<0,01$ & $<0,05$ & 89,9 & $<0,07$ & & 0,62 & $<0,006$ & & \\
\hline PML 175 & PIXEog-04deco16 & goterón & Mamilla 7 & PIXE & $\begin{array}{r}<0,02 \\
\end{array}$ & $\begin{array}{r}0,02 \\
\end{array}$ & $<0,04$ & 99,7 & $<0,06$ & & $<0,2$ & $<0,009$ & & \\
\hline 67580 & PIXEog-16janoog & frag. vástago de anzuelo & \begin{tabular}{|l|} 
Caleta Huelén \\
\end{tabular} & PIXE & $<0,004$ & $<0,005$ & $<0,02$ & 94,2 & $<0,09$ & $\begin{array}{l}<0,1 \\
\end{array}$ & $<0,01$ & $\begin{array}{ll}0,01 \\
\end{array}$ & $<0,007$ & $<0,003$ \\
\hline
\end{tabular}

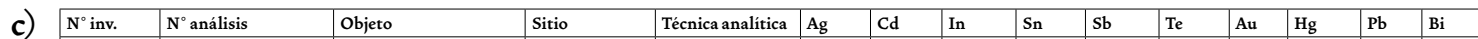

\begin{tabular}{|c|c|c|c|c|c|c|c|c|c|c|c|c|c|c|}
\hline & & & & & & & & & & & & & & \\
\hline PML 173 & PIXEog-04deco12 & frag. vástago de anzuelo & Mamilla 1 & PIXE & 0,04 & $<0,006$ & $<0,006$ & $<0,009$ & 0,2 & $<0,010$ & $<0,2$ & $<0,2$ & $<0,05$ & $<0,03$ \\
\hline 67578 & PIXEog-16jano24 & lingotillo & Mamilla 3 & PIXE & \begin{tabular}{|l|l|}
$<0,004$ \\
\end{tabular} & $<0,005$ & $<0,006$ & $\begin{aligned} 0,008 \\
\end{aligned}$ & $\begin{array}{r}0,004 \\
\end{array}$ & $<0,009$ & \begin{tabular}{|l|l|}
$<0,03$ \\
\end{tabular} & $<0,03$ & \begin{tabular}{ll|l}
$<0,02$ \\
\end{tabular} & $\begin{aligned} 0,02 \\
\end{aligned}$ \\
\hline 67577 & PIXEog-16jano27 & prill & Mamilla 3 & PIXE & $<0,006$ & $<0,007$ & $<0,008$ & 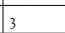 & $<0,005$ & $<0,010$ & $<0,01$ & $<0,02$ & $<0,02$ & $<0,02$ \\
\hline PML_309 & \begin{tabular}{|l} 
PIXEo9-16jano43 \\
\end{tabular} & frag. vást & Mamilla 3 & PIXE & 0,03 & $<0,005$ & $<0,006$ & $<0,04$ & 0,06 & $<0,010$ & $\angle 0,1$ & $<0,1$ & 0,1 & $\begin{aligned}<0,03 \\
\end{aligned}$ \\
\hline $\mathrm{PML}_{310}$ & PIXE09-21 & lámina & Mamilla 3 & PIXE & 0,1 & $\begin{array}{r}<, 004 \\
\end{array}$ & $<0,005$ & , ol & $\begin{array}{r}<0,005 \\
\end{array}$ & $<0,005$ & \begin{tabular}{rl|}
$<0, O I$ \\
\end{tabular} & \begin{tabular}{|c|c|}
$<0,02$ \\
\end{tabular} & \begin{tabular}{cc|c|c|}
$<0,03$ \\
\end{tabular} & \begin{tabular}{r|r|}
$<0,03$ \\
\end{tabular} \\
\hline $\mathrm{PML}_{311}$ & PIXEo9-16jano44 & frag. vásta & Mamilla 7 & PIXI & 0,07 & $<0,02$ & $<0,03$ & 10,2 & $<0,02$ & $<0,04$ & \begin{tabular}{rl|}
$<07$ \\
\end{tabular} & \begin{tabular}{|c|c|}
$<0,08$ \\
\end{tabular} & 0,1 & $\begin{array}{ll}<0,04 \\
\end{array}$ \\
\hline \begin{tabular}{|l|} 
PML 169 \\
\end{tabular} & E09-04decoo9 & lámina & Mamilla 7 & PI & 1,88 & 00,005 & $<0,0$ & $<0,04$ & 0,0 & $<0,02$ & $<0,3$ & $<0,4$ & $<0,05$ & $<0,05$ \\
\hline \begin{tabular}{|l|} 
PML 170 \\
\end{tabular} & MEB_PML170 & frag. vást & Mamilla 7 & SEM-E & & & & 11,4 & & & & & & \\
\hline PML 171 & PIXE09-04decon11 & frag. vást & Mamilla 7 & PIXE & $<0,02$ & 00,005 & $<0,03$ & 12,4 & 0,098 & $<0,02$ & $<0,03$ & $<0,06$ & 0,03 & 0,03 \\
\hline PML 172 & PIXEo9-04deco13 & frag. vástago de anzuelo & Mamilla 7 & PIXE & $<0,02$ & $<0,010$ & $<0,02$ & 6,6 & $<0,02$ & $<0,02$ & $<0,05$ & $<0,04$ & \begin{tabular}{rl|}
$<0,03$ \\
\end{tabular} & $<0,02$ \\
\hline PML $174 \mathrm{~b}$ & \begin{tabular}{|l} 
PIXEo9-04deco15 \\
\end{tabular} & lámina & Mamilla 7 & PIXE & 0,72 & $\begin{array}{r}0,005 \\
\end{array}$ & 00,01 & 5,4 & 0,93 & $<0,02$ & $\begin{aligned}<0,02 \\
\end{aligned}$ & \begin{tabular}{rl|l}
0,08 \\
\end{tabular} & 1,65 & 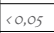 \\
\hline PML 175 & PIXEog-04 & goterón & & PIXE & 0,21 & $\begin{array}{r}<0,007 \\
\end{array}$ & $<0,010$ & $<0,01$ & $<0,02$ & $<0,01$ & $<0,04$ & $<0,04$ & $<0,03$ & $<0,04$ \\
\hline 67580 & PIXEog-16janoog & frag. vástago de anzuelo & Caleta Huelén & PIXE & 0,03 & $<0,008$ & 80,02 & 5,8 & $<0,01$ & $<0,02$ & $<0,03$ & $<0,009$ & \begin{tabular}{ll|l|}
$<0,01$ \\
\end{tabular} & 0,01 \\
\hline
\end{tabular}

d)

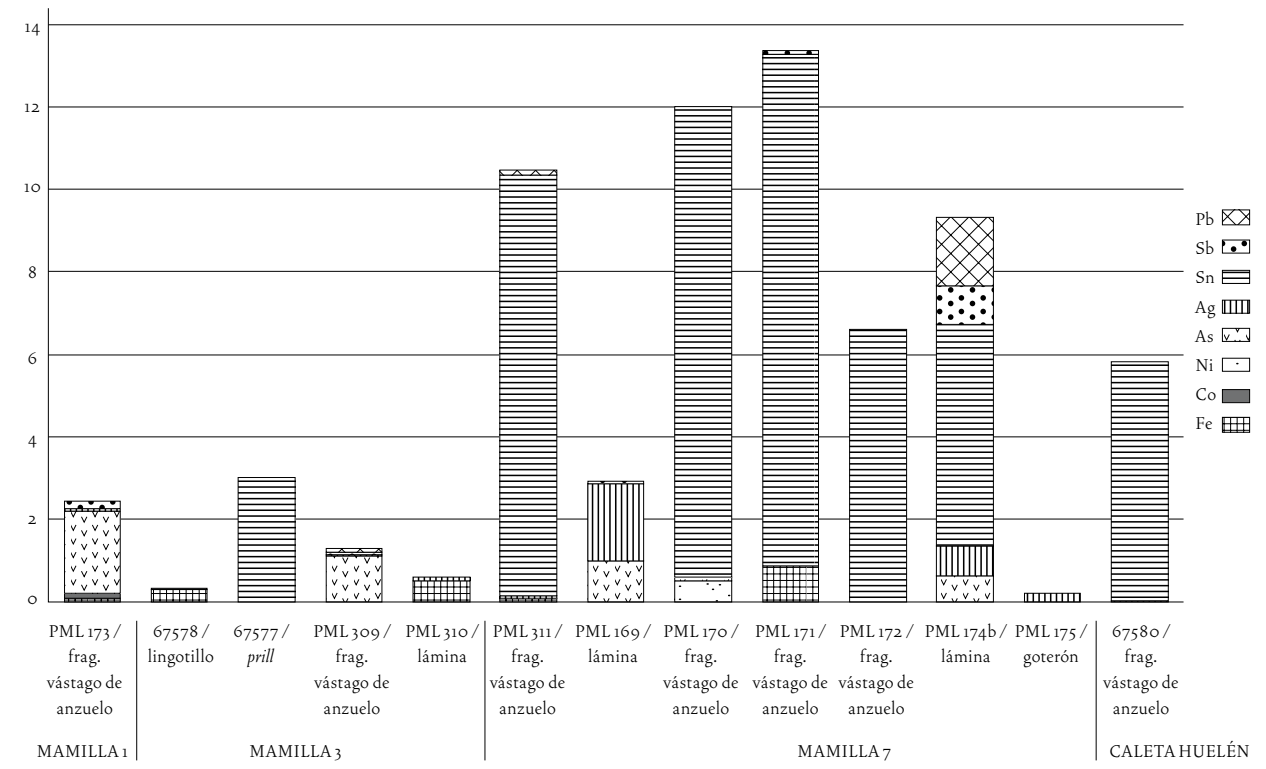

Tabla 3. a, b, c) Resultados de los análisis químicos elementales realizados en el C2RMF de los objetos de Mamilla y Caleta Huelén. El texto en "negrita" indica altos porcentajes de elementos del suelo, pero el resultado de los análisis corresponde más a la composición de los niveles de corrosión que a aquellos del metal original; d) Diagrama de los principales elementos de aleación e impurezas detectados en el cobre.

\footnotetext{
\begin{tabular}{l|l}
34 & $\begin{array}{l}\mathrm{N}^{\circ} 40 / 2010 \\
\text { ESTUDIOS ATACAMEÑos } \\
\text { Arqueología y Antropología Surandinas }\end{array}$
\end{tabular}
} 
a la microscopía en general. La resina facilita la prensión de la muestra y a su vez permite obtener, tras las diferentes fases de pulido, la superficie plana necesaria para la observación microscópica. El pulido fue realizado primero con lijas abrasivas de $\mathrm{SiC}$ de grano 320-4000, y luego con paños impregnados con líquidos abrasivos de polvo de diamante (3, 1, 1/4 MICRON).

El estudio metalográfico del desecho metalúrgico de Mamilla 7 (PML175) demuestra que se trata de un goterón correspondiente a una pequeña porción de metal que cayó posiblemente en el momento de ser vertido. Este goterón posee una microestructura dendrítica, es decir, el metal no ha sido objeto de prácticas de forja o recocido. Lo anterior indica actividades de fundición locales en la quebrada Mamilla, interpretación que ampliaremos y apoyaremos en la discusión y conclusiones.

Cabe señalar que el estado de conservación del anzuelo de Mamilla 7 Capa 8A (PML170) no es estable, su estado de corrosión activa recubre toda la pieza y ha alterado completamente el metal original. Esto ha dificultado la observación ya que de metal son solo algunos granos, los que siguen visibles. Estos granos fueron analizados mediante SEM y los resultados indican un bronce con alta proporción de estaño con presencia de níquel y arsénico como trazas. Por otro lado, el análisis metalográfico permitió identificar la sección original del objeto correspon- diente a una morfología pseudo rectangular típica de los anzuelos prehispánicos (ver Figura 5).

El estado de conservación del anzuelo de la desembocadura del Loa es relativamente estable. Está cubierto por una fina capa de corrosión la cual es más importante en el extremo distal del objeto. Los exámenes metalográficos realizados sobre una de las extremidades del anzuelo $\mathrm{n}^{\circ} \mathrm{C} 67580$ (ver Figura 6) indican una larga cadena operativa de ejecución. El metal denota un trabajo alternado de martillado en frío y de recocido térmico para recuperar la maleabilidad y la ductilidad de la materia. Podemos observar que el metal fue bastante deformado luego del trabajo de martillado en frío y demuestra a su vez eventos de recocido a juzgar por la estructura recristalizada de los granos (Figura 6a). Se observan también importantes inclusiones de sulfuros extremamente deformadas caracterizandose por tener una morfología aplanada y alargada (Figura $6 \mathrm{~b}$ y $6 \mathrm{c}$ ). Esta morfología indica un importante coeficiente de deformación plástica, lo que demuestra que el anzuelo fue intensamente martillado para conseguir su forma final. De acuerdo a lo anterior, podemos afirmar que la fabricación de anzuelos requirió del manejo de un conocimiento acerca de las propiedades de los metales y de las aleaciones, así como de los efectos de las diversas técnicas de manufactura en términos de producir un artefacto apropiado para ser utilizado en la captura y el manejo de los recursos ictiológicos.

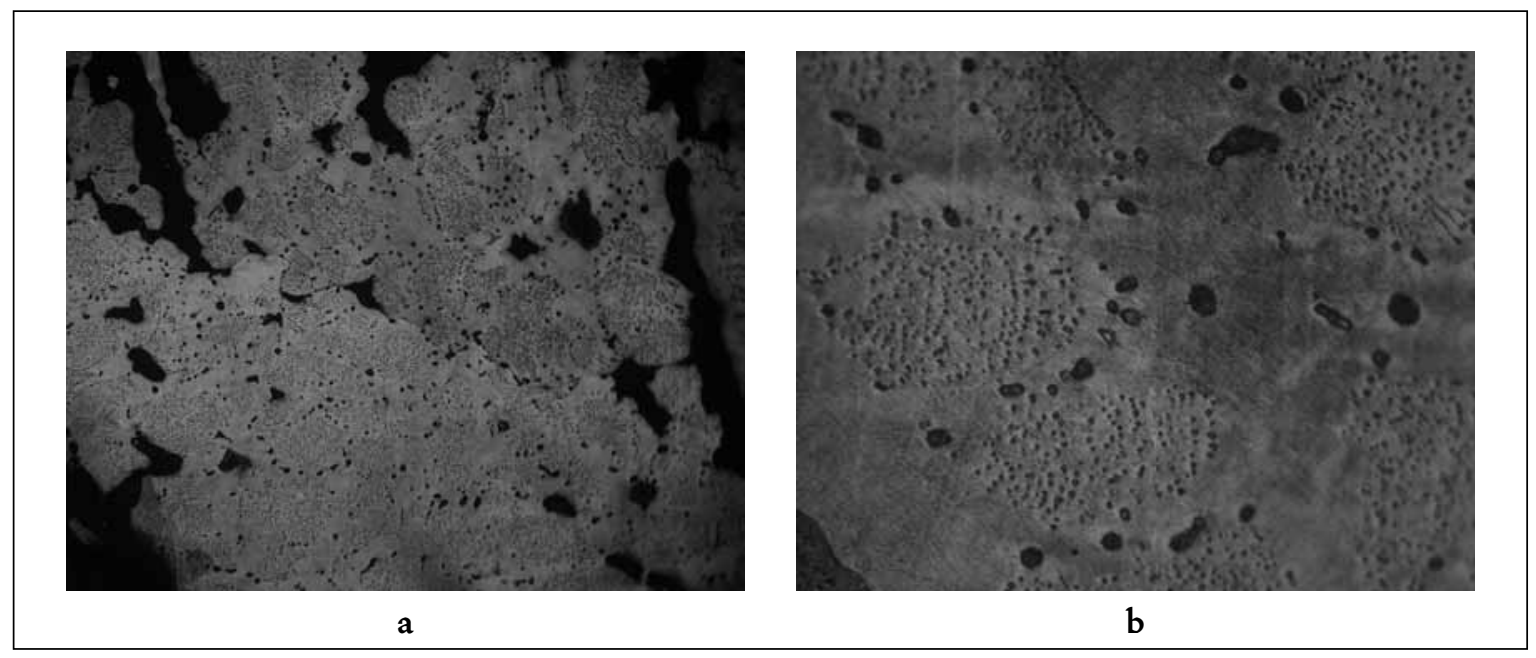

Figura 4. Microestructura del goterón de cobre procedente de Mamilla 7 , Capa 2 (PML175): a) $200 \mathrm{X}$ con ataque químico; b) $400 \mathrm{X}$ sin ataque químico. 


\section{* Discusión}

La composición elemental de los objetos de Mamilla resulta interesante por ser disímil. En efecto, de los cuatro fragmentos de anzuelos provenientes de Mamilla 7 , se aprecia la presencia de dos composiciones elementales diferentes, las cuales corresponden a bronce estañífero con trazas (arsénico, níquel) y bronce estañífero sin impurezas. En estratigrafía, los tres artefactos muestran dos composiciones diferentes. El fragmento más temprano fue recuperado de una capa inmediatamente bajo la fecha calibrada de 1010-1220 DC (PML170) (ver Figura 3). Los análisis composicionales en este artefacto evidenciaron una aleación de cobre con estaño y presencia de arsénico y níquel como trazas. Lo anterior demuestra el uso de anzuelos de bronce estañífero en la costa de Tocopilla a lo menos desde inicios del período Intermedio Tardío. Es interesante constatar que la aleación de cobre y estaño con arsénico y níquel como elementos menores o elementos traza, solo había sido registrada en los Andes en piezas correspondientes a la esfera de interacción Tiwanaku, por lo general herramientas y objetos de prestigio tales como hachas, cuchillos, tupu y agujas (Lechtman 2003; Lechtman y McFarlane 2005). Ya hemos señalado que es poco probable que el metal provenga de la costa de Tocopilla, ya que no hay registros de níquel en los minerales, desechos de fundición o lingotes encontrados en los sitios de la quebrada o sus inmediaciones. Si bien no podemos descartar una elaboración costera en otra localidad, es razonable pensar que dicho anzuelo es resultado de la refundición de un objeto elaborado en las tierras altas (p.e., San Pedro de Atacama) e intercambiado con las poblaciones de la costa arreica. Un análisis de isótopos de plomo permitiría darle mayor sustento a esta interpretación, ya que se ha señalado que la aleación ternaria de cobre, arsénico y níquel de Tiwanaku, o bien de bronces estañíferos con arsénico y níquel como trazas, emplearon menas preferentemente provenientes del altiplano (Lechtman y McFarlane 2005 y 2006). Desgraciadamente, el tamaño de la muestra es sumamente pequeño y el exámen metalográfico reveló un avanzado proceso de corrosión de casi todo el metal original (ver Figura 5). De cualquier manera, queda abierta esta hipótesis que podría darle sustento a la temprana interpretación de Latcham (1936 y 1938) cuando señala que metales de tierras altas estarían siendo refundidos en la costa para fabricar anzuelos u otros elementos asociados a la extracción de recursos litorales.

Los restantes dos fragmentos de anzuelo metálico en estratigrafía de Mamilla 7 provienen de una capa sobre la fecha calibrada de 1010-1220 DC (PML171) y de la capa fechada entre 1440 y 1515 DC (PML172), respectivamente. Se trata en ambos casos de fragmentos pequeños de vástago de anzuelo. Los análisis composicionales demuestran que se trata de bronces estañíferos. Este tipo de aleación fue identificada también en

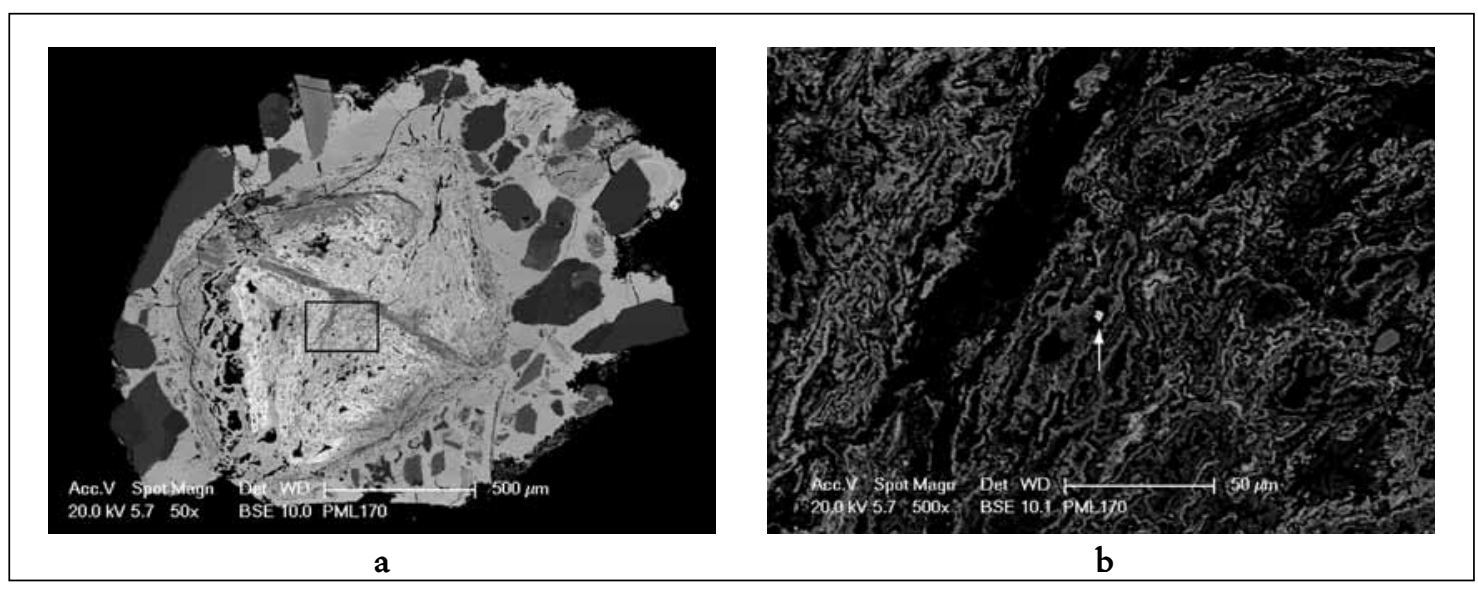

Figura 5. Corte metalográfico del anzuelo de Mamilla 7 Capa 8A (PML170), 100 X sin ataque químico: a) Sección original del artefacto; b) Detalle de la ubicación de los sectores analizados dentro de uno de los dos únicos granos de metal original que quedan en la muestra, debido a la corrosión y mineralización post-depositacional. 
un fragmento de anzuelo proveniente de la superficie de Mamilla 1, otro de superficie de Mamilla 7, un trozo de metal aberrante superficial de Mamilla 7, un anzuelo completo proveniente de Caleta Huelén y una gota de metal o prill de Mamilla 3. A diferencia de la aleación detectada en el fragmento de anzuelo de la Capa 8A (bronce con trazas de $\mathrm{As}$ y $\mathrm{Ni}$ ), la presencia de un prill metálico de cobre con estaño permite pensar en una metalurgia local para la producción de bronce estañífero de alta pureza. Pese a que se trata de un hallazgo superficial, por lo que no podemos saber si dicha metalurgia se desarrolló en el Intermedio Tardío y/o en el Tardío, lo cierto es que la sola presencia de este tipo de aleación permite plantear interesantes preguntas ya que, como es bien sabido, las principales menas de estaño del Área Andina se encuentran en el altiplano del sur de Perú, Bolivia y el Noroeste Argentino, es decir a más de $300 \mathrm{~km}$ de distancia de Tocopilla (Lechtman y McFarlane 2005; Mlynarczyk y Williams-Jones 2005). En trabajos anteriores uno de los autores identificó la recurrente presencia de bronces estañíferos en las colecciones de artefactos metálicos de la costa de Arica, así como la producción local de dicha aleación en el sitio Terraza Sur de Camarones (Figueroa $2010 \mathrm{Ms}$ ). En consecuencia, el estaño pudo llegar a la localidad de Tocopilla desde el altiplano o bien desde la zona de AricaCamarones. Esta segunda alternativa parece razonable dada la presencia tanto en Mamilla 7 como en otras localidades cercanas (Caleta Huelén, Cobija), de alfarerías de la denominada Cultura Arica (Núñez 1984; Salazar et al. 2009; Uribe et al. 2009), así como por los atributos morfológicos y composicionales del anzuelo de Caleta Huelén analizado por nosotros, el que parece haber sido elaborado en los Valles Occidentales.

Futuras investigaciones deberán determinar si el estaño llegó a la costa de Tocopilla en calidad de menas minerales que fueron reducidas localmente, o si llegó a la costa en estado metálico, ya sea aleado con cobre o sin alear. Considerando que en Camarones se están produciendo lingotes de bronce estañífero, es razonable proponer la existencia de un tráfico de lingotes desde dicha localidad hacia Tocopilla y otras zonas del litoral norte de Chile, donde serían posteriormente refundidos para la fabricación de artefactos locales. No obstante, análisis practicados sobre uno de los lingotillos del sitio Mamilla 3 determinaron la presencia de cobre sin alear, por lo que aún no tenemos evidencia de lingotes de bronce en los sitios estudiados. Este último dato abre a su vez una nueva interrogante. Dado que hoy sabemos que hubo producción de bronces estañíferos en Camarones, ¿el lingote de cobre sin alear será producido en Mamilla o recibido localmente como intercambio?

Para responder esta pregunta deberemos tomar en cuenta las restantes evidencias. Si consideramos el fragmento de un artefacto metálico no identificado proveniente de la capa fechada entre 1440-1515 DC en Mamilla 7, vemos que éste fue elaborado a partir de cobre sin alear. Cobres de alta pureza y sin alear fueron identificados también en el desecho metalúrgico de esa misma capa, así como en muestras provenientes de la

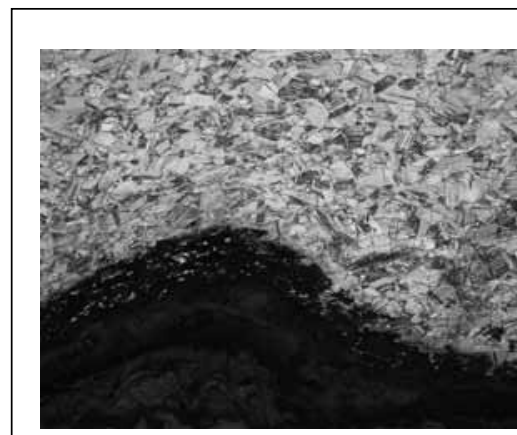

a

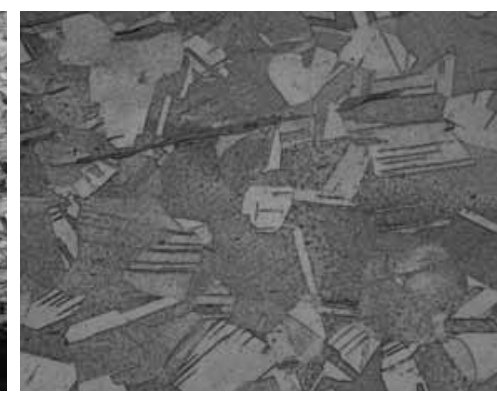

b

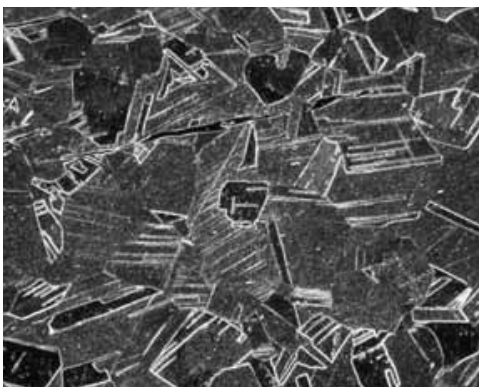

c

Figura 6. Corte metalográfico de anzuelo procedente de Caleta Huelén (C2RMF 65780) con ataque químico: a) (10o X) vista de conjunto en campo claro; b) (400 X) detalle en campo claro; $\mathbf{c}$ (400 X) el mismo detalle en campo oscuro. 
superficie de los sitios Mamilla 1, Mamilla 3, Mamilla 7. Caleta Viuda 7, Paquica Sur 10 y Punta Blanca 1 (ver Tabla 3). Se trata de artefactos terminados, desechos de fundición, gotas o prills y el ya mencionado lingotillo.

A primera vista podría parecer que los prills metálicos y el desecho metalúrgico fueron resultado de la refundición de lingotes de cobre puro y que, por lo tanto, las primeras fases de la cadena operativa pudieron realizarse fuera de la zona costera, siendo esta última receptora de lingotes y preformas. De hecho, la ausencia de escoria en los sitios estudiados parece apoyar esta idea. Sin embargo, una mirada más atenta a los resultados analíticos indica que el lingote se elaboró en un cobre de alta pureza con hierro y azufre como elementos traza, mientras que el desecho metalúrgico, un prill y varios fragmentos de artefactos presentaron una composición dominada por el cobre pero con evidencias de plata, arsénico, antimonio y plomo como impurezas. Desde esta perspectiva, el lingote está más relacionado con el anzuelo histórico de Mamilla, mientras que el desecho metalúrgico y el prill lo están con piezas en estratigrafía y superficie de esa quebrada, pero que no se han identificado aún en otros sitios trabajados.

Todo lo anterior indica que estamos ante a lo menos dos grupos de menas de origen diferente, una de cobre con impurezas de hierro y azufre y la otra de cobre con impurezas de plata, antimonio, arsénico y/o plomo. Estas últimas parecen corresponder a menas locales, ya que se ha reportado la presencia de menas de cobre y plata en la quebrada Mamilla, y minas subactuales fueron reconocidas por nosotros en el sector. Esto es coherente con la alta presencia de estas composiciones químicas en los artefactos y desechos de la propia quebrada Mamilla.

Con todo, los datos anteriores demuestran que durante el período Tardío se desarrollaron actividades metalúrgicas en los diversos sitios de la quebrada Mamilla. Estas actividades incluyeron la reducción y fundición de menas de cobre locales y, en algunos casos, la fundición de bronce estañífero. No sabemos aún si el lingote de cobre llegó a Mamilla en tiempos históricos o prehispánicos. ${ }^{11}$ En este

\footnotetext{
${ }^{11}$ En el caso que el lingote sea de tiempos prehispánicos, una posible fuente de importación de éste sería la aldea La Capilla, en Quillagua. Si bien se carece de datos analíticos para este sitio,
}

contexto, es interesante la presencia de una lámina metálica altamente corroída en la superficie de Mamilla 7, la cual presentó en su composición química cobre, estaño, plata, antimonio, plomo y arsénico. Si bien no tenemos claridad acerca de su cronología, su composición química sugiere que estamos ante prácticas metalúrgicas que fundieron estaño metálico y/o bronce estañífero con las menas de cobre-plata-arsénico-antimonio locales, sintetizando por lo tanto las dos actividades metalúrgicas mencionadas más arriba. Lo cierto es que el objetivo de todas las actividades metalúrgicas prehispánicas habría sido la producción de objetos para la extracción litoral, en especial anzuelos.

La presencia de prills de cobres sin alear asociados a minerales cupríferos en otros sitios de la localidad, indica que esta práctica metalúrgica no fue un hecho aislado en la quebrada Mamilla, sino una actividad recurrente de las poblaciones locales. Los sitios en los cuales se encuentran estas evidencias corresponden a campamentos base (Paquica Norte, Paquica Sur 3, Mamilla 7, Punta Blanca) y campamentos de tarea (Caleta Blanca 5, Caleta Viuda 10, Agua Dulce 7), correspondientes a los períodos tardíos de la prehistoria local. Futuros análisis composicionales más finos deberán demostrar si otras menas de la localidad fueron explotadas también. El hecho de que en estos sitios tampoco aparezca escoria podría deberse a que se están reduciendo menas de muy alta ley.

En síntesis, puede afirmarse que los grupos cazadores recolectores y pescadores tardíos de la costa arreica practicaban una metalurgia local de baja escala, la cual incluía la reducción de menas locales y la fundición de lingotes metálicos producidos en otras localidades del norte de Chile (posiblemente Camarones y/o Quillagua a juzgar por las evidencias conocidas a la fecha). A partir de las metalografías realizadas en el anzuelo de Caleta Huelén y de tantos otros ejemplares, puede afirmarse que la fabricación de anzuelos en la costa implicó una larga cadena operativa de ejecución, ya que el metal analizado demuestra un trabajo alternado de martillado en frío y de recocido térmico para recuperar la maleabilidad y la ductilidad de la materia. Vale decir, el anzuelo analizado fue intensamente martillado

en él se ha constatado la presencia sistemática de escorias metalúrgicas y lingoteras tanto en superficie como en estratigrafía (Cervellino y Téllez 1980). 
para conseguir su forma final lo que sugiere una clara intencionalidad y un conocimiento experto que permitió obtener un metal apropiado para los requerimientos mecánicos y funcionales de la captura y manejo de los recursos ictiológicos (Figueroa $2010 \mathrm{Ms}$ ).

\section{$*$ Conclusiones}

La metalurgia andina ha sido caracterizada como una tecnología simbólica desarrollada por sociedades complejas, orientada principalmente a la producción de bienes de estatus que participaron activamente en los procesos de legitimación y reproducción de la desigualdad social (Lechtman 1984 y 1993; Núñez 1999; González 2004).

Este trabajo demuestra que sociedades que habitaron la geografía andina pero que no formaron parte integral de su mosaico cultural adaptaron la tecnología desarrollada en las tierras altas y la adaptaron a sus necesidades y contexto cultural propio. Tal es el caso de los grupos de pescadores, cazadores y recolectores costeros de los períodos Intermedio Tardío y Tardío de la costa arreica del norte de Chile, y particularmente del área de Tocopilla, donde se ha centrado nuestra investigación. Aquí apreciamos cómo los grupos locales accedieron a productos metálicos semiterminados (lingotes) y/o a objetos metálicos como parte de las redes de interacción mantenidas con las poblaciones de oasis interiores y/o los grupos de pescadores agricultores de los Valles Occidentales. Sin embargo, al menos desde el período Tardío, los grupos costeros de Tocopilla desarrollaron también una producción local de metales, la cual incluyó todas las fases de la cadena operativa, desde la minería hasta la producción de objetos terminados. La fabricación de estos artefactos requirió de conocimientos importantes acerca de las propiedades de la materia y las ventajas funcionales de distintos tipos de metales y aleaciones.

El propósito de esta metalurgia local no fue la elaboración de objetos suntuarios. El intercambio con poblaciones de tierras altas permitió acceder a bienes que ciertamente pueden ser considerados de estatus, tales como cuchillos, hachas o placas, entre otros. Pero la metalurgia desarrollada por las poblaciones locales tuvo por objetivo fabricar instrumentos orientados a la captura y procesamiento de recursos costeros. La principal categoría artefactual representada son los anzuelos y, si bien no existe suficiente investigación para afirmarlo, es probable que los anzuelos metálicos reemplacen parcial o totalmente a los tradicionales anzuelos de espina de cactus, hueso o concha de las poblaciones locales.

La pesca con anzuelos metálicos debió otorgar ventajas a los pescadores locales en términos de la mayor resistencia mecánica y durabilidad de estas piezas en comparación con sus contrapartes de otras materias primas, lo que se pudo traducir en la captura de peces más grandes y/o en el uso más intensivo de estos artefactos. En este sentido, la proliferación de una tecnología metalúrgica local durante el Tardío bien pudo estar relacionada con la necesidad de aumentar la producción local de peces para el intercambio con poblaciones interiores $y / o$ tributo a las autoridades partícipes de la administración incaica en la costa. Ciertamente la pesca con instrumental metálico debió tener connotaciones de prestigio, pero su popularidad en los contextos costeros tardíos debe entenderse también como respuesta a la necesidad de generar mayores excedentes de recursos.

Esta situación parece darse en otros contextos de la costa norte, y particularmente en la zona de Arica-Camarones (Figueroa $2010 \mathrm{Ms}$ ). No obstante, a diferencia de dicha zona, en la costa arreica la producción local de metales no se concentró en un sector específico (p.e., Terraza Sur de Camarones), por lo que no hay evidencias de un control de la producción. Por el contrario, si bien las evidencias son más profusas en la quebrada Mamilla que en otros sitios de la costa de Tocopilla, nuestras prospecciones en un tramo de $40 \mathrm{~km}$ de costa entre Punta Atala y Paquica identificaron a lo menos otros seis sitios con presencia de minerales de cobre y prills metálicos en superficie. Considerando los análisis químicos que demuestran que dichos prills metálicos son de cobre de alta pureza sin alear, proponemos que forman parte de una tecnología metalúrgica local desarrollada durante el período Tardío. Si esto es correcto, los artefactos metálicos (principalmente anzuelos) están siendo fabricados por los grupos locales en diversos puntos al mismo tiempo, aunque siempre en baja escala. Como hemos visto, las prácticas metalúrgicas se desarrollaron tanto en los campamentos base como en algunos campamentos de tarea, lo cual sugiere que estamos ante una tecnología orientada a abastecer las 
necesidades específicas surgidas en los grupos móviles locales, seguramente como resultado de la pérdida o fractura de piezas en uso.

En el contexto del mundo andino, entonces, estamos ante una situación social previamente no descrita: la existencia durante los períodos Intermedio Tardío y/o Tardío de la costa arreica de una tecnología metalúrgica desarrollada por poblaciones altamente móviles y organizadas en sociedades no divididas, la cual se orienta exclusivamente a satisfacer necesidades inmediatas en la producción de artefactos que participan a su vez en la generación de excedentes costeros.

Muchas interrogantes quedan aún sin respuesta, pero esperamos que investigaciones futuras permitan comprender mejor la tecnología metalúrgica litoral (combustibles minerales empleados, tipo de estructuras de combustión, aleaciones usadas, entre otros), así como su inserción dentro de un modo de vida tradicional del desierto costero del norte de Chile.

Agradecimientos Esta investigación ha sido financiada por la Dirección de Investigación de la Universidad de Chile a través del Proyecto DI SOC 2007 20-02 y por el Proyecto FONDECYT 1080666. Agradecemos a los colegas que participaron en diversas campañas de terreno y laboratorio, en especial a Camila Palma, Felipe Fuentes, Nicolás Lira, Laura Olguín, Mariela Pino, Valentina Varas y Nicole Fuenzalida. Un agradecimiento especial para Claudio Castellón, Paul Maluenda, Eldan Tapia y la Sra. Eddie, por el apoyo brindado durante nuestras campañas de terreno. Por último, agradecemos al profesor Claudio Aguilar (UACH), por su ayuda en la preparación de las muestras para análisis metalográficos y por su interés en nuestra investigación arqueometalúrgica.

\section{* Referencias citadas}

ALDUNATE, C., V. CASTRO y V. VARELA, 2008. San Bartolo y Cobija: Testimonios de un modo de vida minero en las tierras altas y la costa de Atacama. Estudios Atacameños, Arqueología y Antropología Surandinas 35: 97-118.

ÁLVAREZ, L., 1959. Descripción de los objetos metalúrgicos y líticos obtenidos de una tumba de La Lisera. Boletín del Museo Regional de Arica 1.

1981. Metalurgia prehispánica en el extremo norte de Chile. Revista Parina 1: 33-38.

1992-93. Metalurgia prehispánica inca en un sector costero marginal del Imperio. Diálogo Andino 11-12: 67-76.

ARCE, I., 1997 [1930]. Narraciones históricas de Antofagasta. Lama Industrial S.A., Iquique.

BERMÚdEZ, O., 1966. Orígenes históricos de Antofagasta. Prensas de la Editorial Universitaria, Santiago.

BITTMAN, B., 1977. Notas sobre poblaciones de la costa del Norte Grande chileno. En Aproximación a la etnohistoria del norte y tierras adyacentes, J. M. Casassas (Ed.), pp. 56-115. Universidad del Norte, Antofagasta.

CAJÍAS, F., 1977. La provincia de Atacama (1825-1842). Instituto Boliviano de Cultura, La Paz.
CERVELLINO, M. y F. TÉLLEZ, 1980. Emergencia y desarrollo de una aldea prehispánica de Quillagua, Antofagasta. Contribución Arqueológica 1.

DURÁN, E., R. PERRET y G. CONCHA, 1980. Análisis metalográfico de anzuelos de cobre. Noticiario Mensual del Museo Nacional de Historia Natural XXV (290): 10-12.

DURÁN, A., I. KUSMANIC y N. MONTENEGRO, 1995. Caleta Errázuriz, un área de asentamiento de pescadores del período Tardío en la II región. Boletín Ocasional del Museo Nacional de Historia Natural 2: 7-21.

FIGUEROA, V., 2010 Ms. La métallurgie préhispanique des pêcheurs du littoral Pacifique dans le Chili Septentrional, Thèse de Doctorat, Université de Paris I Panthéon-Sorbonne. En preparación.

FIGUEROA, V., Y. COQUINOT, B. MILLE y D. SALAZAR, 2009. Metalurgia prehispánica litoral en Caleta Camarones (Arica-Parinacota, Chile): Estudio arqueométrico de los "crisoles-moldes”. Actas del XII Congreso Geológico Chileno, pp. 1-4. Santiago.

FIGUEROA, V., I. MONTERO y S. ROVIRA, 2010. Estudio tecnológico de objetos procedentes de Cerro Turquesa (San José del Abra, II región). Actas del XVII Congreso Nacional de Arqueología Chilena (2006), vol. 2, pp. 1135-1147. Valdivia. 
GONZÁLEZ, L., 2004. Bronces sin nombre. La metalurgia prehispánica en el Noroeste Argentino. Ediciones Fundación CEPPA, Buenos Aires.

HORTA, H., 2000. Diademas de plumas en entierros de la costa del norte de Chile: ¿Evidencias de la vestimenta de una posible parcialidad pescadora? Chungara, Revista de Antropología Chilena $32(2): 235-243$

LATCHAM, R., 1909. El comercio precolombino en Chile i otros países de América. Anales de la Universidad de Chile 126:377-439.

1910. Los changos de las costas de Chile. Imprenta Cervantes, Santiago.

1936. Metalurgia atacameña. Boletín de Museo Nacional de Historia Natural 15: 107-151.

1938. Arqueología de la región atacameña. Prensas de la Universidad de Chile, Santiago.

LATORRE, E., M. T. PLAZA y R. RIVEROS, 2007. El caso de la Colección Lodwig: Caracterización de un conjunto de piezas metálicas prehispánicas del litoral de Caldera (III región, Chile). Werkén 11: 89-106.

LECHTMAN, H., 1984. Andean value systems and the development of prehistoric metallurgy. Technology and culture 25 (1): 1-36.

1993. Technologies of power: The Andean case. En Configurations of power in complex society, P. Netherly y J. Henderson (Eds.), pp. 244-280. Cornell University Press, Ithaca.

1996. Arsenic bronze: Dirty copper or chosen alloy? A view from the Americas. Journal of Field Archaeology 23 (4): 477-514.

2003. Middle Horizon bronze: Centers and outliers. En Patterns and process, L. van Zelst (Ed.), pp. 248-268. Smithsonian Center for Materials Research and Education, Washington D.C.

LECHTMAN, H. y A. McFARLANE, 2005. La metalurgia del bronce en los Andes Sur Centrales: Tiwanaku y San Pedro de Atacama. Estudios Atacameños 30: 7-27.

2006. Bronce y redes de intercambio andino durante el Horizonte Medio: Tiwanaku y San Pedro de Atacama. En Esferas de interacción prehistóricas y fronteras nacionales modernas: Los Andes Surcentrales, H. Lechtman (Ed.), pp. 500-550. Instituto de Estudios Peruanos (IEP), Lima.

MAKSAEV, V. y M. ZENTILLI. 2002. Chilean strata-bound Cu(Ag) deposits: An overview. En Hydrothermal iron oxide coppergold and related deposits: A global perspective, T. Porter (Ed.), pp. 185205. PGC Publishing, Adelaide.
MARTÍNEZ, N., J. RIVERA y F. RIVERA, 2005. El ayer de Cobija y Gatico. Presencia de la Iglesia Católica. Ediciones Universitarias, Universidad Católica del Norte, Antofagasta.

MAYER, E., 1986. Armas y herramientas de metal prehispánicas en Argentina y Chile. En Materialien zur Allgemeinen und Vergleichenden Archaelogie, Band 38 Verlag, München.

MOSTNY, G., 1964. Arqueología de Taltal. Epistolario de Augusto Capdeville con Max Uhle. Fondo Histórico y Bibliográfico J. T. Medina, vols. I y II. Santiago.

MLYNARCZYK, M. S. J. y A. E. WILLIAMS-JONES, 2005. The role of collisional tectonics in the metallogeny of the Central Andean tin belt. Earth and planetary. Science Letters 240: 656-667

MUÑOZ, I., 1989. Perfil de la organización económica social en la desembocadura del río Camarones: Período Intermedio Tardío e Inca. Chungara 22: 85-111.

NÚÑEZ, L., 1971. Secuencia y cambio en los asentamientos humanos de la desembocadura del río Loa, en el norte de Chile (informe preliminar de un proyecto arqueológico en desarrollo). Boletín de la Universidad de Chile 112:3-25.

1984. Secuencia de asentamientos prehistóricos del área de Taltal. Revista Futuro 8: 28-76.

1987. Tráfico de metales en el Area Centro Sur Andina: Factos y expectativas. Cuadernos del Instituto Nacional de Antropología 12: 73-107.

1999. Valoración minero-metalúrgica circumpuneña: Menas y mineros para el Inka rey. Estudios Atacameños 18: 177-222.

2006. La orientación minero-metalúrgica de la producción atacameña y sus relaciones fronterizas. En Esferas de interacción prehistóricas y fronteras nacionales modernas: Los Andes Surcentrales, H. Lechtman (Ed.), pp. 205-260. Instituto de Estudios Peruanos (IEP), Lima.

PONCE, E., 2002. Mazas prehispánicas de metal: Sur de Perú y extremo norte de Chile. Chungara, Revista de Antropología Chilena 34 (2): $215-223$.

PONCE, E., L. ÁLVAREZ, J. JIMÉNEZ, R. TORRICO y M. MOLLO, 1996. Metalurgia precolombina del cobre: Norte de Chile, Caleta Camarones. Revista Facultad de Ingeniería UTA 3-11-16.

SAlAZAR, D., C. PALMA, H. SAlinAS, F. FUENTES, J. L. GUENDON y C. CASTELLÓN, 2010. Reconstrucción de la secuencia ocupacional de la quebrada Mamilla, costa de Tocopilla, norte de Chile. Werkén 13:323-346. 
SCHIAPPACASSE, V. y H. NIEMEYER, 1989. Avances y sugerencias para el conocimiento de la prehistoria tardía en la desembocadura del valle de Camarones (región de Tarapacá). Chungara 22: $63-84$.

SPAHNI, J. C. 1967. Recherches archéologiques a l'embouchure du rio Loa (côte du Pacifique, Chili). Journal de la Société des Américanistes 56:179-239.

TARRAGÓ, M., L. GONZÁLEZ y J. NASTRI, 1997. Las interacciones prehispánicas a través del estilo. El caso de la iconografía santamariana. Estudios Atacameños 14: 223-242.
URIBE, M., L. ADÁN, C. AGÜERO, C. MORAGAS y F. VILCHES, 2009. Current research in Tarapacá region. Andean Past 9:329-335

VIVALLO, W. y F. HENRÍQUEZ, 1998. Génesis común de los yacimientos estratoligados y vetiformes de cobre del Jurásico Medio a Superior en la cordillera de la Costa, Antofagasta, Chile. Revista Geológica de Chile 25 (2): 199-228.

ZAMBRA, J., S. KOJIMA, S. ESPINOZA y A. DEFINIS, 2007. Angélica copper deposit: Exotic type of mineralization in the Tocopilla Plutonic Complex of the Coastal cordillera, Northern Chile. Resource Geology 57 (4): 427-434. 